\title{
Nanoparticle formation and emission during laser ablation of ceramic tiles
}

\author{
Apostolos Salmatonidis ${ }^{\mathrm{a}, \mathrm{d}}$, Mar Viana ${ }^{\mathrm{a}}$, Noemí Pérez ${ }^{\mathrm{a}}$, Andrés Alastueya ${ }^{\mathrm{a}}$ Germán F. de la Fuente ${ }^{\mathrm{b}}$, Luis \\ Alberto Angurel ${ }^{b}$, Vicenta Sanfélix ${ }^{c}$, Eliseo Monfort ${ }^{c}$ \\ a Institute of Environmental Assessment and Water Research, Spanish Research Council (IDÆA-CSIC), 08034, \\ Barcelona, Spain.

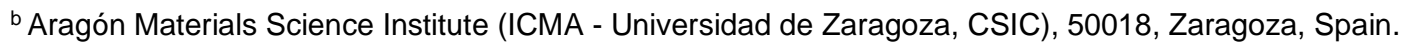 \\ ${ }^{c}$ Institute of Ceramic Technology (ITC)- AICE - Universitat Jaume I, 12006 Castellón, Spain. \\ d University of Barcelona, Faculty of Chemistry, Department of Chemical Engineering and Analytical Chemistry, \\ 08028, Barcelona, Spain.
}

*corresponding author: Apostolos Salmatonidis, apostolos.salmatonidis@idaea.csic.es

\begin{abstract}
Pulsed laser ablation (PLA) is a widely used technology, for surface structuring and tile decoration in the ceramic industry. During PLA, nanoparticles (NP $<100 \mathrm{~nm}$ ) are unintentionally released and may impact exposure. This work aims to understand the mechanisms controlling NP formation and release during ablation of different types of ceramic tiles, using different laser setups (near$\mathrm{IR}$ and mid-IR). The measurements took place at laboratory and pilot-plant-scale, with varying laser wavelength, frequency, velocity, and pulse duration. In total, the combination of 4 types of ceramic tiles and 2 lasers was assessed. Particle number concentration and size distribution (SMPS with nano-DMA, DiSCmini, butanol-CPC) and particle mass concentration (DustTrakDRX) were monitored. Samples were also collected for morphological and chemical characterization (TEM/EDX). High particle number concentrations were detected $\left(3.5^{\star} 10^{4} / \mathrm{cm}^{3}\right.$ to $\left.2.5^{\star} 10^{6} / \mathrm{cm}^{3}\right)$ for all of the tiles and under both laser setups. Particle formation $(<10 \mathrm{~nm})$ by nucleation was detected, and secondary amorphous $\mathrm{SiO}_{2}$ nanoparticles (>10 nm) were formed and released during ablation of the porcelain tiles. Different release mechanisms were identified: during ablation with the near-IR laser particles were emitted through melting and nucleation, while emissions from the mid-IR laser were attributed to melting and mechanical shockwaves. Particle number and mass emissions were dependent on the tile surface characteristics (e.g., porosity, crystallinity) and chemical properties. This work is potentially relevant from the point of view of exposure mitigation strategies in industrial facilities where PLA is carried out.
\end{abstract}

Keywords: nanoparticles, ceramic industry, laser ablation, formation mechanisms

\section{Introduction}

Laser ablation is a technology with widespread applications at global scale, examples of which are precision microfabrication (Sugioka, Meunier, \& Pique, 2010), surface structuring (Lahoz, de la Fuente, Pedra, \& Carda, 2011) characterization and analytical techniques (Russo, Mao, Gonzalez, Zorba, \& Yoo, 2013). Pulsed laser ablation (PLA), in particular, is a state-of-the-art method used for ceramic tile processing in order to achieve designs with enhanced durability and aesthetic properties (Pascual et al., 2005). However, this technology is known to generate 
nanoparticle (NP, $<100 \mathrm{~nm}$ ) emissions to workplace air and the environment (A. S. Fonseca et al., 2015, 2016). Based on current literature, understanding the sources and mechanisms controlling the formation and release of process-generated nanoparticles (PGNP) in industrial settings is becoming increasingly relevant, in order to minimize potential hazards (Hameri, Lahde, Hussein, Koivisto, \& Savolainen, 2009; van Broekhuizen, 2012; Viitanen, Uuksulainen, Koivisto, Hämeri, \& Kauppinen, 2017). Adverse health effects of NPs have been extensively described in the literature (Heal, Kumar, \& Harrison, 2012), and the main exposure route to NPs is inhalation. Specifically, Oberdörster (2001) showed that in certain cases NP can cause severer pulmonary inflammation than fine particles, while Weichenthal (2012) observed significant associations between NP and acute cardiovascular morbidity. Consequently, numerous industrial processes which generate NP emissions have received increasing attention in recent years (Curwin \& Bertke, 2011; Demou, Peter, \& Hellweg, 2008; Ana Sofia Fonseca et al., 2014; Gandra, Miranda, Vilaa, Velhinho, \& Teixeira, 2011; Gómez, Irusta, Balas, \& Santamaria, 2013; Koivisto et al., 2012; van Broekhuizen, 2012). Pfefferkorn et al (2009) described the potential for exposure to ultrafine aerosols during industrial welding operations, and Viana et al. (2017) reported analogous potential during atmospheric thermal spraying. Additionally, Voliotis et al. (2014) proved that traditional ceramic production processes emit particles $<100 \mathrm{~nm}$, and awareness was raised towards this specific industrial sector.

In order to characterize and minimize exposure, the mechanisms generating particle emissions must be understood. During laser ablation intense electromagnetic fields interact with matter and atoms are selectively driven off by thermal or non-thermal mechanisms (Phipps, 2007). NP emissions during PLA can be mainly associated with three phenomena:

- Nucleation: atoms, ions and clusters which emanate from the plasma plume (Noël, Hermann, \& Itina, 2007), can act as nuclei and through different growth routes (coalescence, diffusional, coagulation) form secondary particles (Polte, 2015). Gaseous precursors which may originate from direct sublimation (solid-to-gas) and from evaporation of melt (liquid-to-gas), can condensate and form new particles (A. S. Fonseca et al., 2015).

- Melt expulsion (droplets): Temperature differences between the surface and the body of the material create localised pressure gradients (Czotscher \& Vollertsen, 2016; Zhigilei, Lin, \& Ivanov, 2009), which force droplets of melt to get extruded from the tile, cool down rapidly and, due to surface tension, form spherical particles.

- Shockwaves: Mechanical shockwave cracking of grains can contribute to the emission of primary particles. Particle removal is associated to ablation and poor thermal resistance, which is typical for porcelain tiles (Lahoz et al., 2011). Thermal shock and the consequent ejection of micro-scaled grains occurs due to differences in thermal expansion coefficients (Pascual-Cosp, Ramírez del Valle, Garciá-Fortea, \& Sánchez-Soto, 2002; Pascual-Cosp, Ramírez Del Valle, García Fortea, \& Sánchez Soto, 2001; Pascual et al., 2005).

In addition to these, particle aggregation and agglomeration mechanisms are also determinants of particle size distribution after formation and emission (Koch \& Friedlander, 1989; Lushnikov, Maksimenko, \& Pakhomov, 1989; Sivayoganathan, Tan, \& Venkatakrishnan, 2012). 
The current study aims to characterize the mechanisms determining NP emissions during PLA of ceramic tiles by correlating fundamental ablation phenomena with particle release. A parametric study was designed to assess the influence of material properties (composition, structural characteristics), laser sources (wavelength) as well as process parameters (pulse duration, frequency) on NP formation and emissions in terms of size, particle number and mass concentration. The ultimate goal of the present work was to increase the understanding of the mechanisms governing NP formation during laser ablation, which may facilitate the design of more efficient exposure mitigation measures.

Table 1. Ceramic tiles under study (Abbreviations, $1^{\text {st }}$ letter: Glaze, $2^{\text {nd }}$ letter: Tile, $3^{\text {rd }}$ letter: Colour)

\begin{tabular}{ccccc}
\hline Abbreviation & Full Name & Tile & Porous & Main Components ${ }^{\star \star}$ \\
\hline UPG & Unglazed Porcelain Grey & Porcelain stoneware & no & $71 \% \mathrm{SiO}_{2}, 19 \% \mathrm{Al}_{2} \mathrm{O}_{3}$ \\
UAW & Unglazed Alumina White & Alumina & yes & $97 \% \mathrm{Al}_{2} \mathrm{O}_{3}$ \\
UBW & Unglazed Biscuit White & $\begin{array}{c}\text { Non-sintered/biscuit } \\
\text { porcelain }\end{array}$ & yes & $70 \% \mathrm{SiO}_{2}, 20 \% \mathrm{Al}_{2} \mathrm{O}_{3}$ \\
GER & Glazed Earthenware Red & Earthenware & yes & $57 \% \mathrm{SiO}_{2}, 12 \% \mathrm{ZnO}$ \\
\hline
\end{tabular}

${ }^{*}$ The chemical composition refers only to the glaze, and not the body of the GER tile, since that was the part processed by the laser

${ }^{* *}$ The full chemical characterization can be found in Table S1 in Supplementary material.

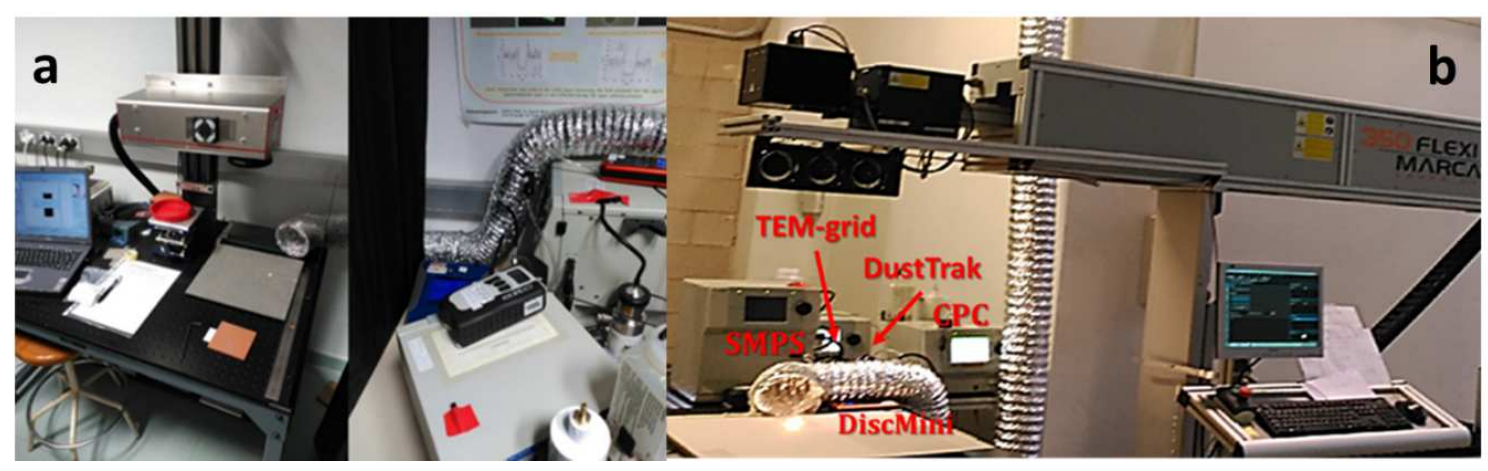

Figure 1. Experimental setup of (a) the laboratory-scale with the near-IR laser, and (b) the pilot-plant with the mid-IR laser. The distribution of the different particle monitoring instrumentation is presented. 


\section{Materials and methods}

The laser ablation experiments took place at the Materials Science Institute of Aragón "ICMA" (CSIC-University of Zaragoza) in Zaragoza (Spain), with an overall duration of 5 working days.

Table 2. Experimental sequence

\begin{tabular}{|c|c|c|c|}
\hline Date & $\begin{array}{l}\text { Energy } \\
\text { settings }\end{array}$ & Tile & Comments \\
\hline \multicolumn{4}{|c|}{ Near-IR laser } \\
\hline 07-02-2017 & Low & UPG & - \\
\hline 07-02-2017 & Low & UAW & 2 different tiles $\left(1^{\text {st }}+2^{\text {nd }}\right.$ rep., $3^{\text {rd }}$ rep. $)$ \\
\hline 07-02-2017 & Low & UBW & Heating switched on \\
\hline 08-02-2017 & High & UPG & - \\
\hline 08-02-2017 & High & UAW & $\begin{array}{l}3 \text { different tiles-different for each } \\
\text { repetition }\end{array}$ \\
\hline 08-02-2017 & High & UBW & - \\
\hline \multicolumn{4}{|c|}{ Mid-IR laser } \\
\hline 09-02-2017 & Standard & UBW & $\begin{array}{l}\text { Filter extraction with the same } \\
\text { flow }\end{array}$ \\
\hline $10-02-2017$ & Standard & UPG & $1^{\text {st }}$ repetition - briefly stopped \\
\hline $10-02-2017$ & Standard & GER & - \\
\hline $10-02-2017$ & Low & GER & $\begin{array}{c}\text { In addition to the standard energy } \\
\text { settings }\end{array}$ \\
\hline
\end{tabular}

\subsection{Tile and laser combinations}

Four different ceramic tiles were used as target materials (Table 1). Porcelain stoneware (UPG; $71 \% \mathrm{SiO}_{2}, 19 \% \mathrm{Al}_{2} \mathrm{O}_{3}$; Table $\mathrm{S} 1$ in Supplementary Material) is currently the ceramic tile of highest commercial interest, as it exhibits higher technical and functional performance and greater versatility, allowing this tile to be used in both indoor and outdoor environments (International Organization for Standardization, 2012; Sánchez, García-Ten, Sanz, \& Moreno, 2010). Porous ceramics (e.g. alumina, UAW; $97 \% \mathrm{Al}_{2} \mathrm{O}_{3}$; Table S1), on the other hand are used in high temperature applications such as thermal insulation in the cement, steel, aluminium, iron-alloy and petrochemical industries (Salomão, Bôas, \& Pandolfelli, 2011). Glaze is a vitreous coating $\left(56 \% \mathrm{SiO}_{2}, 12 \% \mathrm{ZnO}, 7 \% \mathrm{ZrO}_{2}\right.$; Table S1) that seals the inherent porosity of the tile's body material and serves as a colorant or waterproofing agent and it was a component of the earthenware tiles studied in this work. Each target material has different chemical composition as shown in Table S1 (Supplementary material). Furthermore, the different optical properties of the tiles result in very different absorbance of the incident energy, which means that the laser treatment efficiency will vary depending on the material itself. In addition, this efficiency strongly depends on the laser wavelength. Therefore, two different laser systems with different wavelengths were used:

A. Near-IR laser (Easy Laser, Model: YLPM-1-4x200-20-20, Ytterbium fiber laser, Wavelength: $1064 \mathrm{~nm}$, nominal power $20 \mathrm{~W}$ ) at laboratory scale, with which the UPG, UAW and UBW tiles were processed (Fig. 1a). 
B. Mid-IR laser (Easy Laser, Model: 350 Flexi Marcatex, Slab-type $\mathrm{CO}_{2}$ laser, Wavelength: 10.6 $\mu \mathrm{m}$, nominal power $350 \mathrm{~W}$ ) at pilot-plant scale, used to process the UPG, UBW and GER tiles (Fig. 1b). Although, the UAW tiles were optically compatible with this laser, strong thermal stresses were generated inducing tile fracture. Hence, the UAW tiles were not processed with this laser.

Mid-IR lasers (i.e. $\mathrm{CO}_{2}$ ) are widely used in industrial applications for cutting and welding, while nIR lasers are generally used for engraving (Andreeta, Cunha, Vales, Caraschi, \& Jasinevicius, 2011). Applications include scribing, engraving, and marking of a wide variety of materials, including glass and ceramics. Finally, the difference in power between these lasers was considered advantageous as they allowed for the assessment of NP formation at two different scales (laboratory and pilot plant, Fig. 1).

\subsection{Experimental}

In order to ensure the reproducibility of the results all experiments were performed in triplicate and consisted of 20-minutes ablation followed by a 10-minutes settle-down time. Localized air extraction was installed close to the target tiles (Fig. 1), both in the laboratory and the pilot plant, at a distance of approximately 10 centimetres from the initial point of the laser beam. The extraction intensities for all the experiments were kept at a constant flow speed of $3.5 \mathrm{~m} / \mathrm{s}$. The laser beam started marking from an initial point and covered a rectangular surface with a continuous parallel line movement. The tile surface treated by the laser was always untreated, i.e., the laser always moved towards the untreated part of each tile and there was no spatial overlap from one laser shot to another. The spacing between lines is shown in Table S2 in Supplementary Material.

Laser ablation was carried out under two energy settings with the near-IR laser: high and low, detailed process parameters are listed in Table S2 in Supplementary material. In the case of "high energy" configuration higher pulse durations were used. These two different energy settings were used to observe the effects of processing parameters on the same target materials, under the same laser wavelength. Table 2 summarizes the sequence of experiments. As opposed to the near-IR laser, only one set of laser processing parameters was applied for the target tiles with the mid-IR laser. However, in the case of GER samples a low energy set of process parameters were also applied. The reason for that was to study the effect of the energy input to the excessively high emissions in this particular case (GER).

\subsection{Real-time measurements}

Particle monitoring was carried out simultaneously in four different locations, using the following instrumentation:

1) Emission source

- Scanning Mobility Particle Sizer (TSI SMPS 3080, TSI 3776 CPC) with a nano-DMA (Differential Mobility Analyser) to monitor particle size distribution from $3 \mathrm{~nm}$ to $100 \mathrm{~nm}$ with a 3-minute resolution. 
- Butanol Condensation Particle Counter (TSI model 3775) to monitor total particle number concentration in the range of $4 \mathrm{~nm}-3 \mu \mathrm{m}$ with 1-minute resolution.

- Miniature diffusion size classifier "DiSCmini" (TESTO AG), which detects particles ranging from $10 \mathrm{~nm}$ to $700 \mathrm{~nm}$, monitoring total particle number, mean particle diameter and lung deposited surface area.

- DustTrak DRX Aerosol Monitor (TSI model 8533), simultaneously monitoring sizesegregated particle mass concentrations from 0.1 to $15 \mu \mathrm{m}$. The instrument was set to a 1-minute resolution.

- Samples were collected on TEM grids (Agar scientific Quantifoil 200 Mesh Au) for offline morphological and physicochemical characterization. A Leland pump (SKC Inc.) with a flow of 5 litters/minute was connected with a cassette (SKC inlet diameter 1/8 inch and filter support pads of diameter $25 \mathrm{~mm}$ ) to which the TEM grid was attached.

2) Near Field

- Electrical mobility spectrometer (Nanoscan-SMPS, TSI model 3910) to monitor particle size distribution. The size range of the instrument is $10 \mathrm{~nm}-420 \mathrm{~nm}$ and the time resolution 1 minute.

- Optical Particle Sizer (TSI model 3330) monitoring particle optical size distribution in the 0.3-10 $\mu \mathrm{m}$ range, with 1-minute time resolution.

- Miniature diffusion size classifier "DiSCmini" (TESTO AG), see above.

- Samples were also collected on TEM grids, see above.

3) Far-Field

- Mini Wide Range Aerosol Spectrometer (GRIMM mini-WRAS) monitoring particle size diameter from $10 \mathrm{~nm}-35 \mu \mathrm{m}$. This instrument also provides $\mathrm{PM}_{1}, \mathrm{PM}_{2.5}$ and $\mathrm{PM}_{10}$ mass concentrations.

- Miniature diffusion size classifier "DiSCmini” (TESTO AG), see above.

- DustTrak DRX Aerosol Monitor (TSI model 8533)

4) Outdoor

- Miniature diffusion size classifier "DiSCmini" (TESTO AG), see above.

- DustTrak DRX Aerosol Monitor (TSI model 8533), see above.

The emission source measurements for both lasers were performed inside the extraction tube at a distance of approximately $0.5 \mathrm{~m}$ from the incident laser beam. It is not possible to provide a precise distance since the laser beam was moving away from the extraction tube during the process. At the emission source all the instruments used inlets with tubing no longer than $10 \mathrm{~cm}$. For the DiSCmini transparent conductive "Tygon" tubing was used (Asbach et al., 2016), while conductive silicone tubing was used for the rest of the instruments. In the near-field, far-field and outdoor locations no tubing was used for any of the online instruments. The potential limitations of the Dusttrak monitors were taken into account (Rivas et al., 2017). 


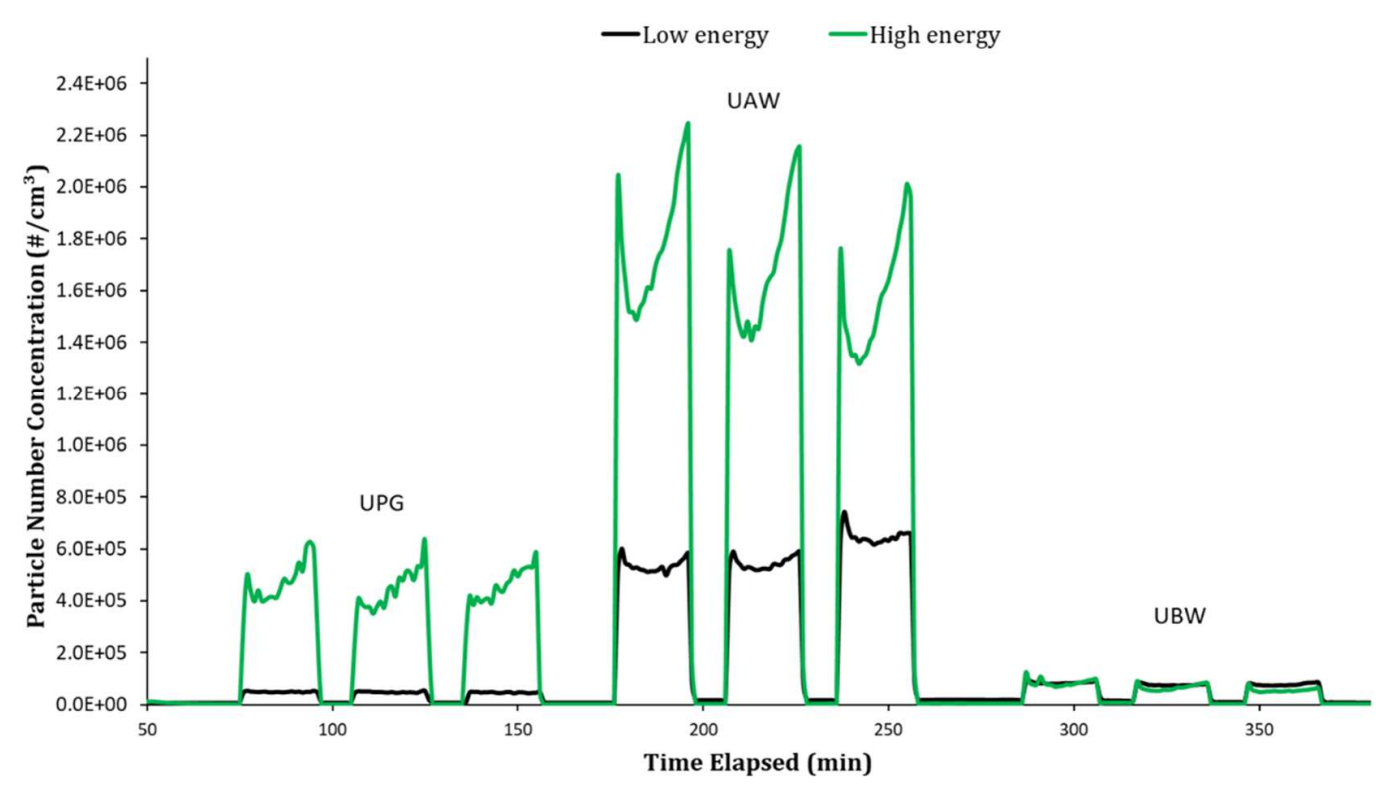

Figure 2. Particle number concentrations $(4 \mathrm{~nm}-3 \mu \mathrm{m})$ during low energy and high energy ablation of the different tiles with the near-IR laser.

\section{Results}

In this section time series of the different experimental cycles, categorized by laser and energy settings, are described in terms of particle size distribution, particle number as well as mass concentration. The results presented correspond to the emission source only, given that the data collected in the near-field and far-field locations did not show any significant impacts from NP emissions in the worker area or in the background. The lack of impact was due to the high efficiency of the exposure mitigation mechanisms in place in this industrial setup (localized extraction). Thus, under the conditions assessed in this work, no significant impact on worker exposure was detected.

\subsection{Near-IR laser}

\subsubsection{Experiments carried out under low energy settings}

The time series of particle number concentration $(N)$ in the size range $4 \mathrm{~nm}-3 \mu \mathrm{m}$ of three different tiles (UPG, UAW and UBW) are shown in Fig. 2. Emissions in terms of particle number (N) were evident in all cases as soon as the laser beam hit the target, and for the entire duration of the ablation run (20 minutes). Likewise, once the laser beam stopped, a rapid drop of $\mathrm{N}$ occurred allowing clear separation of each repetition. The highest emissions were registered during the ablation of UAW tiles $\left(6.1 * 10^{5} / \mathrm{cm}^{3}\right)$, which released almost 6 times more particles than UBW $\left(7.6^{*} 10^{4} / \mathrm{cm}^{3}\right)$ and 11 times more than UPG $\left(4.6^{*} 10^{4} / \mathrm{cm}^{3}\right)$. The UBW showed higher emissions than UPG, but still in the same order of magnitude. The mean particle diameters in the range 10$700 \mathrm{~nm}$ (DiSCmini) were 59.6, 69.9 and $84.7 \mathrm{~nm}$ for the UPG, UAW and UBW tiles respectively.

The UPG and the UBW exhibited a very high reproducibility over their repetitions, while in the case of UAW the last repetition showed higher emissions in terms of particle number concentration than the first two. The reason behind this difference is that the two first repetitions 
were performed on the two opposite sides of the same tile (front and back), while the third one was performed on a different tile. Even though tiles of the same material ( $\alpha$-alumina) were used, crystallographic analysis of different UAW tiles showed that in some cases there was a minor phase of $\mathrm{MgAl}_{2} \mathrm{O}_{4}$ (spinel, Fig. S1) which may have affected the emissions. The ablation of UAW tiles requires melting at $2050^{\circ} \mathrm{C}$ (Nedialkov, Atanasov, Sawczak, \& Sliwinski, 2003) which is lower than the $\mathrm{MgAl}_{2} \mathrm{O}_{4}$ spinel melting point $\left(2135^{\circ} \mathrm{C}\right)$. Therefore, it may be concluded that a potentially higher melting temperature resulted in lower NP emissions.
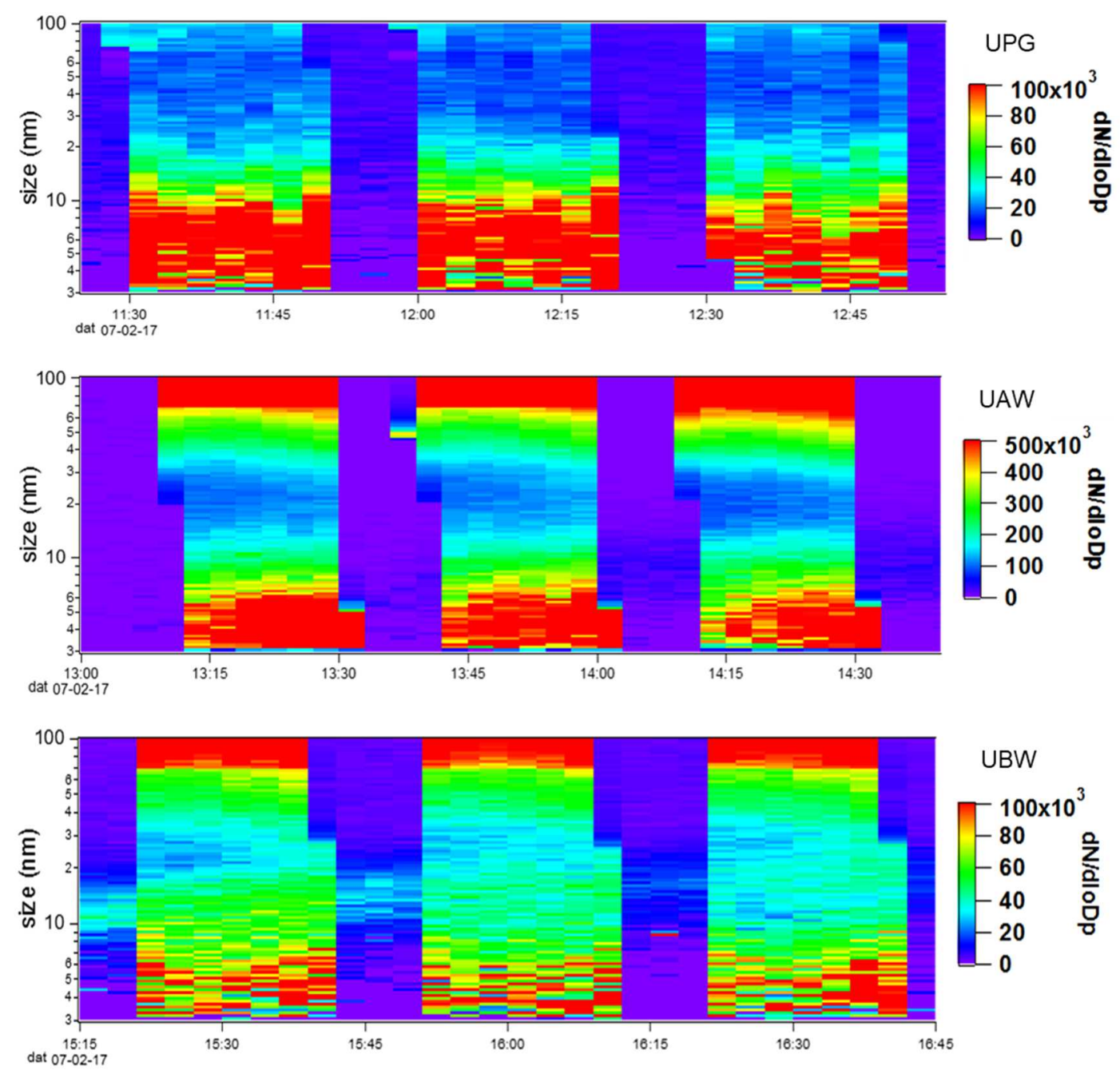

Figure 3. Size distribution (3-100 $\mathrm{nm}$ ) of particles emitted during ablation with the near-IR laser under low energy settings

In order to explain the differences in the emissions of the different tiles their particle size distribution patterns were assessed (Fig. 3).

During the ablation of UPG tiles under low energy settings, high NP concentrations in the size bins $<10 \mathrm{~nm}$ were recorded $\left(80-100 * 10^{3} / \mathrm{cm}^{3}\right)$, evidencing nanoparticle emissions. The small sizes of NP detected suggest that they may source from nucleation from atoms and ions (Noël et al., 2007) as well as from gaseous precursors (A. S. Fonseca et al., 2015, 2016). As described 
above, in this scenario gaseous precursor emissions may originate from direct sublimation and from evaporation of the melt (cf. section 4). Hence, nucleation through different routes may be identified as the dominant emission mechanism during ablation of UPG tiles.

In the case of the UAW tiles, two separate modes with high concentration of different sized particles may be observed. The first mode, from 3 to $10 \mathrm{~nm}\left(300-50010^{3} / \mathrm{cm}^{3}\right)$, can be attributed to particle nucleation. As Nedialkov et al. (2003) found strong evidence of melt during pulsed laser ablation of alumina, the second mode from 40 to $100 \mathrm{~nm}\left(300-50010^{3} / \mathrm{cm}^{3}\right)$ can be attributed to the direct emissions of molten droplets (cf. section 4). Based on Figure 3 it may be concluded that two mechanisms, melting and nucleation, had similar contributions to the emissions of alumina in the size range 3-100 $\mathrm{nm}$.

The particles emitted during ablation of the UBW tiles consisted mainly of primary NPs ( $>40 \mathrm{~nm})$, with a relatively minor contribution from nucleation. The irregular emission pattern for particles $<5$ $\mathrm{nm}$ could have been influenced by instrumentational noise. The emission of nanoparticles (40$100 \mathrm{~nm}$ ), similar to the case of UAW, can be attributed to the melt expulsion from the surface of the irradiated tile. The melt formed and continued to be heated was then evaporated and the resulting vapours could have condensed to form $<10 \mathrm{~nm}$ NPs (Fig. 3). The particle concentrations in the size range $>40 \mathrm{~nm}\left(60-10010^{3} / \mathrm{cm}^{3}\right)$ suggests that the dominant mechanism in this case was primary emissions due to melting of the tile surface.

The TEM analysis of the particles collected during ablation of the different tiles is presented in Fig. 4. The main components of porcelain are silica and alumina (over 90\%, Table S1). Nanoparticles released from UPG ablation (Fig. 4a) were mainly silica nanoparticles, with traces of sodium, which is a minor component in porcelain. The newly formed silica nanoparticles with diameters $\mathrm{Dp} \leq 10 \mathrm{~nm}$ were in agreement with the SMPS size distribution and the nucleation mechanism proposed. The UAW tiles (Fig. 4b) released spherical particles originating from the ejection of melt droplets ( $>40 \mathrm{~nm}$ ), as well as nanoparticles formed by the condensation of melt vapours $(<10 \mathrm{~nm})$, which is consistent with the size distribution (Fig. 3). Similar is the case for the UBW (Fig. 4c), for which larger and spherical particles were detected ( $>40 \mathrm{~nm})$, alongside with smaller NPs $(<10 \mathrm{~nm})$. As shown in Figure 4, agglomerates were also detected originating from the emission process or as a sampling artefact on the TEM grids. Due to the high particle concentrations monitored it was expected that particle aggregation and agglomeration should have taken place under this kind of particle emission scenario (Max L. Eggersdorfer, Kadau, Herrmann, \& Pratsinis, 2012; Maximilian L. Eggersdorfer \& Pratsinis, 2014).

Particle mass concentrations were also monitored under low energy settings in four different size ranges (Fig. 5). UAW tiles released the highest mass concentrations during ablation. Contributions from the different mass size fractions can be clearly distinguished, confirming that particles of different sizes were emitted. The $\mathrm{PM}_{1} / \mathrm{PM}_{10}$ ratio for the UAW tiles was $87.5 \%$, indicating that the main contributor to emissions was PM1. UPG and UBW tiles exhibited relatively low emissions in terms of mass, with all PM fractions contributing respectively less than $25 \mu \mathrm{g} / \mathrm{m}^{3}$. 


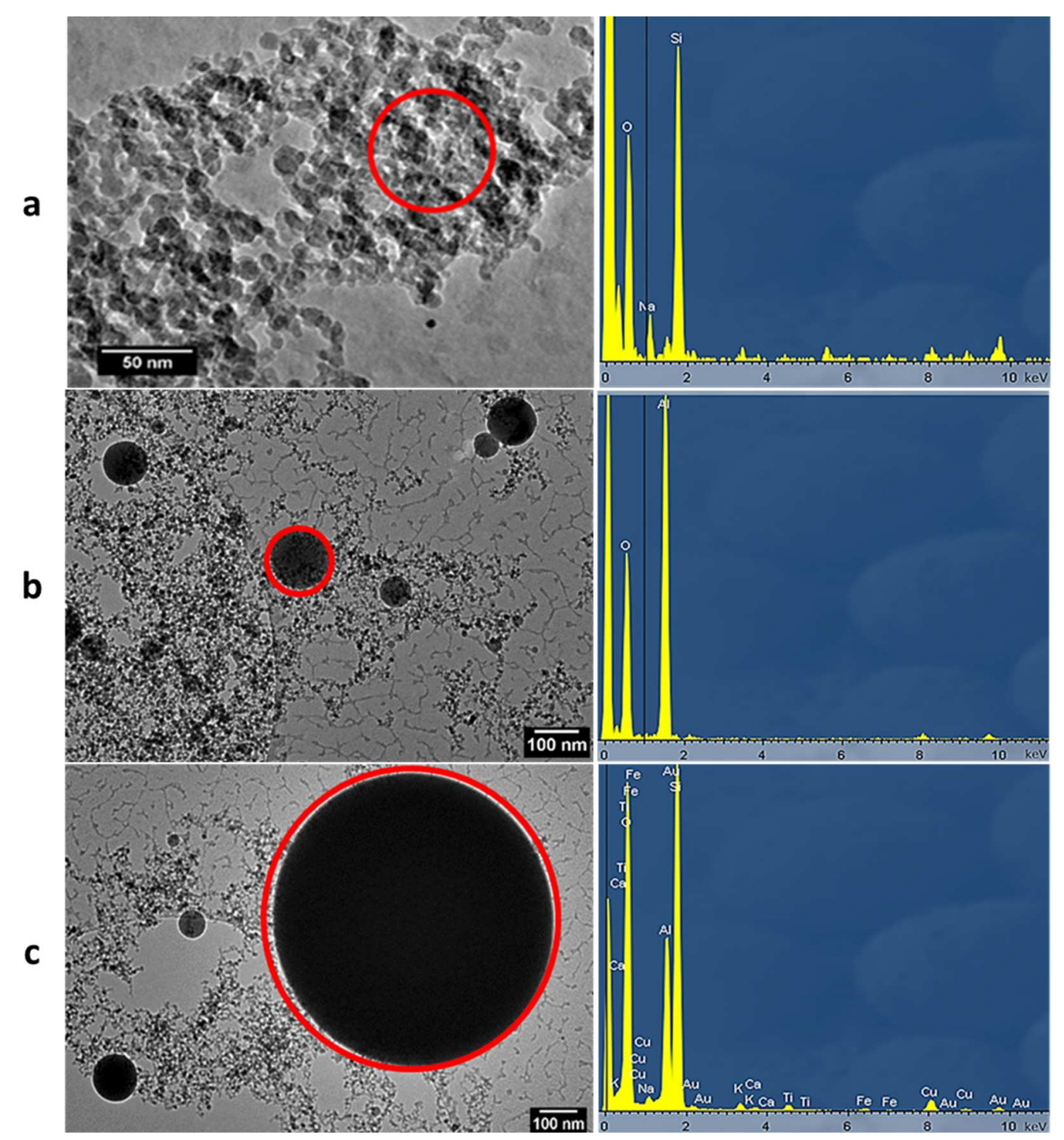

Figure 4. TEM images (right) and EDX spectra (left) of particles released during ablation under low energy settings, sourcing from: UPG (a), UAW (b), UBW (c) tiles

For both of these materials the ratio $\mathrm{PM}_{1} / \mathrm{PM}_{10}$ was approximately the same ( $\left.\approx 80 \%\right)$, indicating a slightly higher contribution from larger particles $\left(\mathrm{PM}_{10}\right)$ than the UAW tiles, probably originated from the ejection of grains due to generation of shockwaves. For porcelain tiles differences in thermal expansion coefficients between the matrix (glassy phase in the case of porcelain) and dispersed particles (quartz and alumina) or crystalline phases formed during this thermal process (mullite), producing strong compressive stresses on the glassy phase (Carty \& Senapati, 1998). Specifically, for both the UPG and UBW tiles the presence of cracks around quartz particles was observed (Fig. S3), which suggests that under mechanical aggression these particles could be easily dislodged. Even though the grain ejection mechanism has a very limited contribution to the emissions in terms of particle number, the few large particles emitted may have a significant impact in terms of particle mass concentration. 


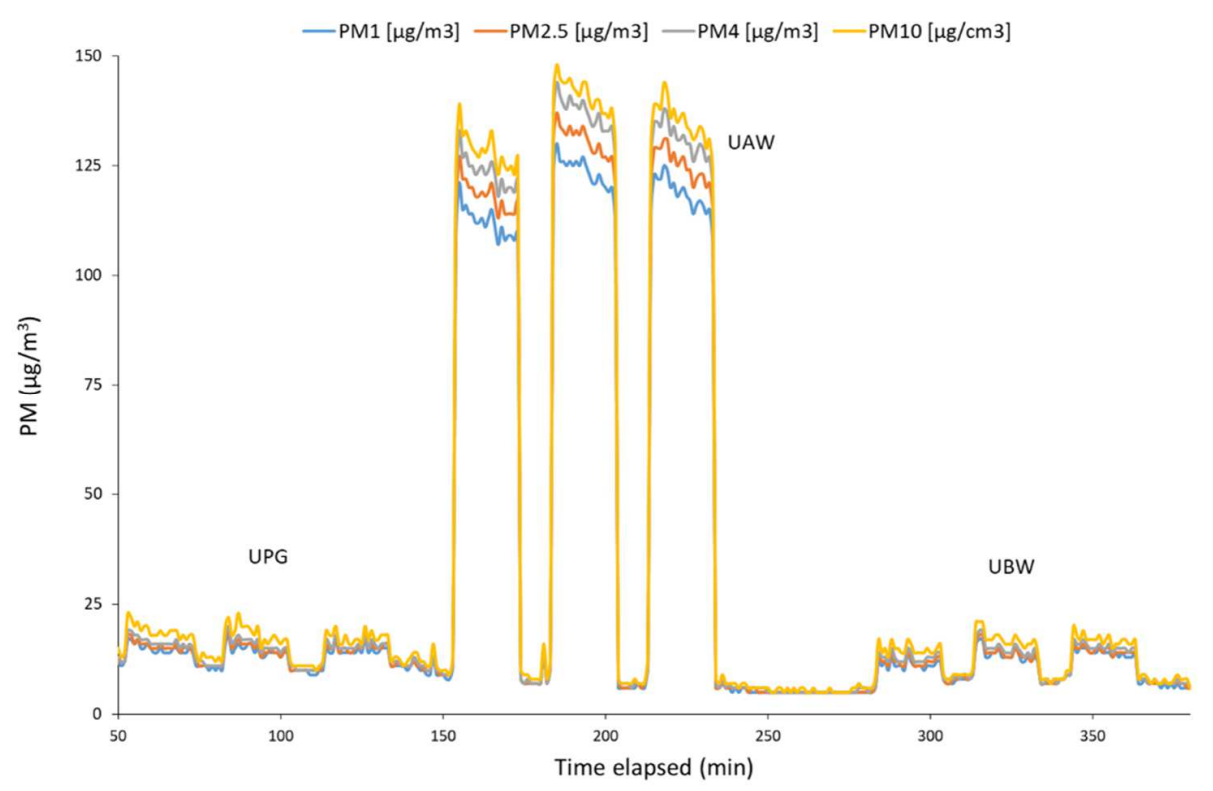

Figure 5. Particle mass concentrations during ablation with the near-IR laser under low energy settings

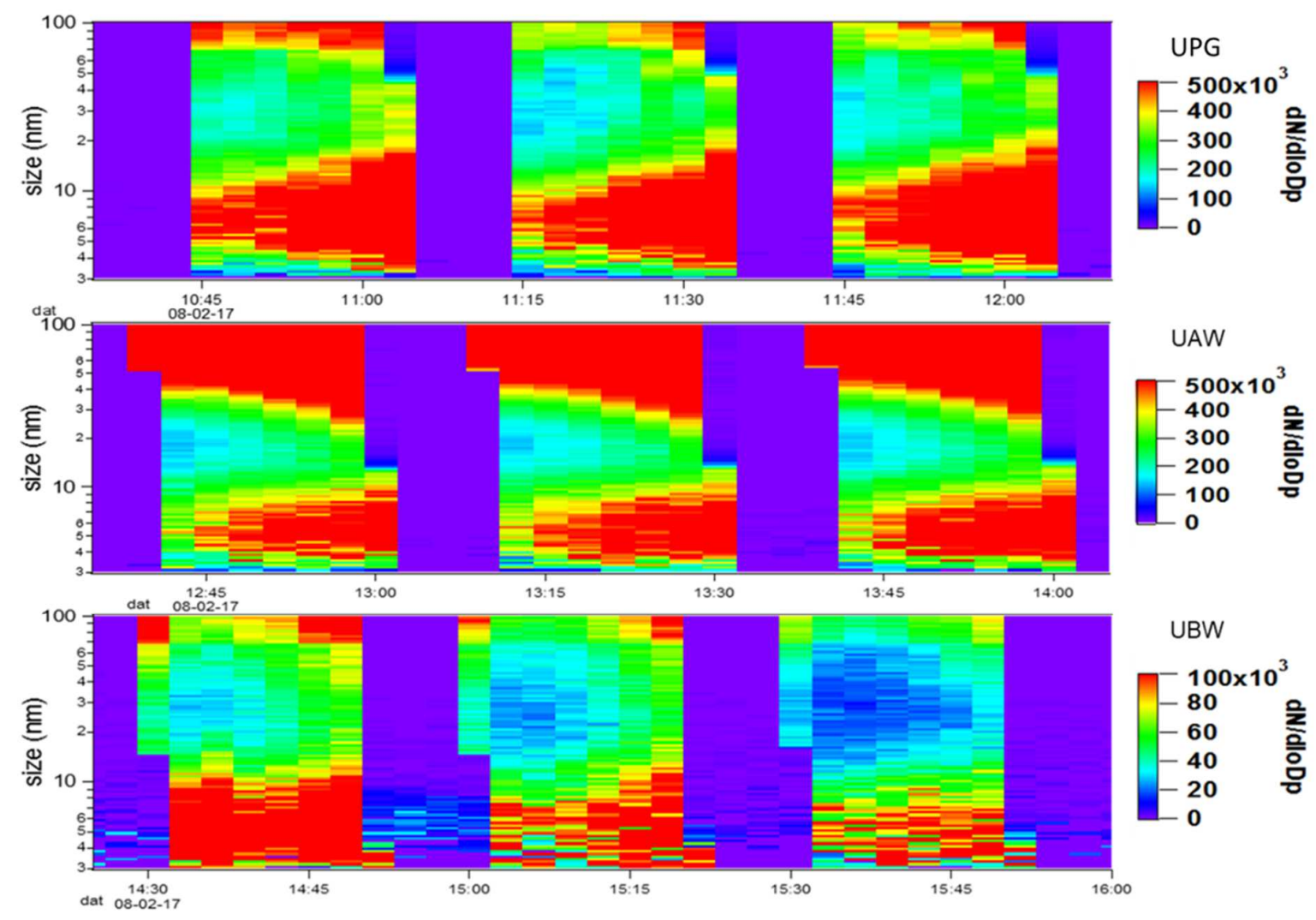

Figure 6. Size distribution (3-100 nm) of particles emitted during ablation with the near-IR laser under high energy settings 


\subsubsection{Experiments carried out under high energy settings}

Higher energy settings were expected to have a major effect on ablation as higher temperatures, more intense and expanded plasmas, were introduced.

NP emissions in terms of particle number concentration were much higher under high energy settings in comparison to low energy settings for UAW and UPG tiles, while they were in the same range for UBW (Fig. 2). A good reproducibility was achieved and the patterns were similar to the ones obtained from the lower energy settings experiments. Specifically, for UAW tiles particle number concentrations under high energy settings increased by approximately a factor of three $\left(1.7^{\star} 10^{6} / \mathrm{cm}^{3}\right)$ and for UPG by one order of magnitude $\left(4.5^{\star} 10^{5} / \mathrm{cm}^{3}\right)$ compared to low energy settings. In the size range 10-700 nm mean diameters for the UPG and UBW tiles (Fig. S2 in Supplementary material) increased by approximately $20 \mathrm{~nm}$ from the respective low energy values (Table 3) indicating a similar change in the particle release mechanisms for this size range.

In terms of particle size distribution (3-100 nm, Fig. 6), different patterns were observed. NPs released from UPG tiles showed high concentrations in the size range 3-15 nm, which were interpreted as sourcing from new particle formation. This mechanism is similar to the one described for the low energy settings (Section 3.1.1), although with higher concentrations. The latter may be explained by the fact that more intense and expanded plasma plume released larger amount of nuclei, which led to a higher number of newly formed particles (cf. section 4). In addition, higher rates of gaseous emissions were also expected due to higher energy, leading to enhanced new particle formation. Finally, the increased temperatures probably resulted in the melting of the surface of the tile and this led to the ejection of small droplets $(30-100 \mathrm{~nm}, 300$ $500^{*} 10^{3} / \mathrm{cm}^{3}$ ) due to the pressure gradient. As a result, Fig. 6-UPG shows the prevalence of new particle formation, with a shift of the specific mode to larger particle diameter over time compared to low energy settings (from 5-10 nm to 3-20 nm), together with a higher contribution of NPs in the $>60 \mathrm{~nm}$ size bins probably originating from emission of droplets $\left(500^{*} 10^{3} / \mathrm{cm}^{3}\right)$. One trait of these emissions, detected also for UAW under high-energy settings (Figure 6), was the evolution of particle number concentrations as a function of time, with increasing numbers of particles between approximately 3-10 nm and 30-60 nm. A similar pattern was observed for GER tiles with the mid-IR laser (Figure 10), for particles between 20-40 nm. These patterns could be related to new particle formation, growth, agglomeration, or linked to sampling artefacts, but the data available at present is not sufficient to extract robust conclusions. Further research would be necessary to understand this temporal pattern which was observed for a subset of laser-tile combinations.

The high energy settings had a similar influence on the UAW tiles, and a shift towards primary emissions was observed. Under low energy settings the dominant formation mechanism was melting for UAW tiles (Fig. 3), and this became even more evident with the increased energy input (Fig. 6). The presence of NPs $<10 \mathrm{~nm}\left(3.1^{*} 10^{8} / \mathrm{cm}^{3}\right)$ was also detected, but their relative contribution was much lower than that of particles in the $30-100 \mathrm{~nm}$ size range $\left(7.2^{*} 10^{8} / \mathrm{cm}^{3}\right)$.

A completely different pattern in terms of particle size distribution was observed for the UBW tiles. While NPs $>70 \mathrm{~nm}$ dominated emissions under the low energy settings $\left(100^{*} 10^{3} / \mathrm{cm}^{3}\right.$, Fig. 3$)$, when higher energy was applied the results showed dominance of NPs $<10 \mathrm{~nm}\left(100^{*} 10^{3} / \mathrm{cm}^{3}\right.$, Fig. 6). As the plasma plume was expanded it favoured a higher rate of new particle formation, 
but at the same time it hindered the energy transfer from the laser to the surface of the tile, thus limiting the expulsion of melt droplets $(>70 \mathrm{~nm})$.

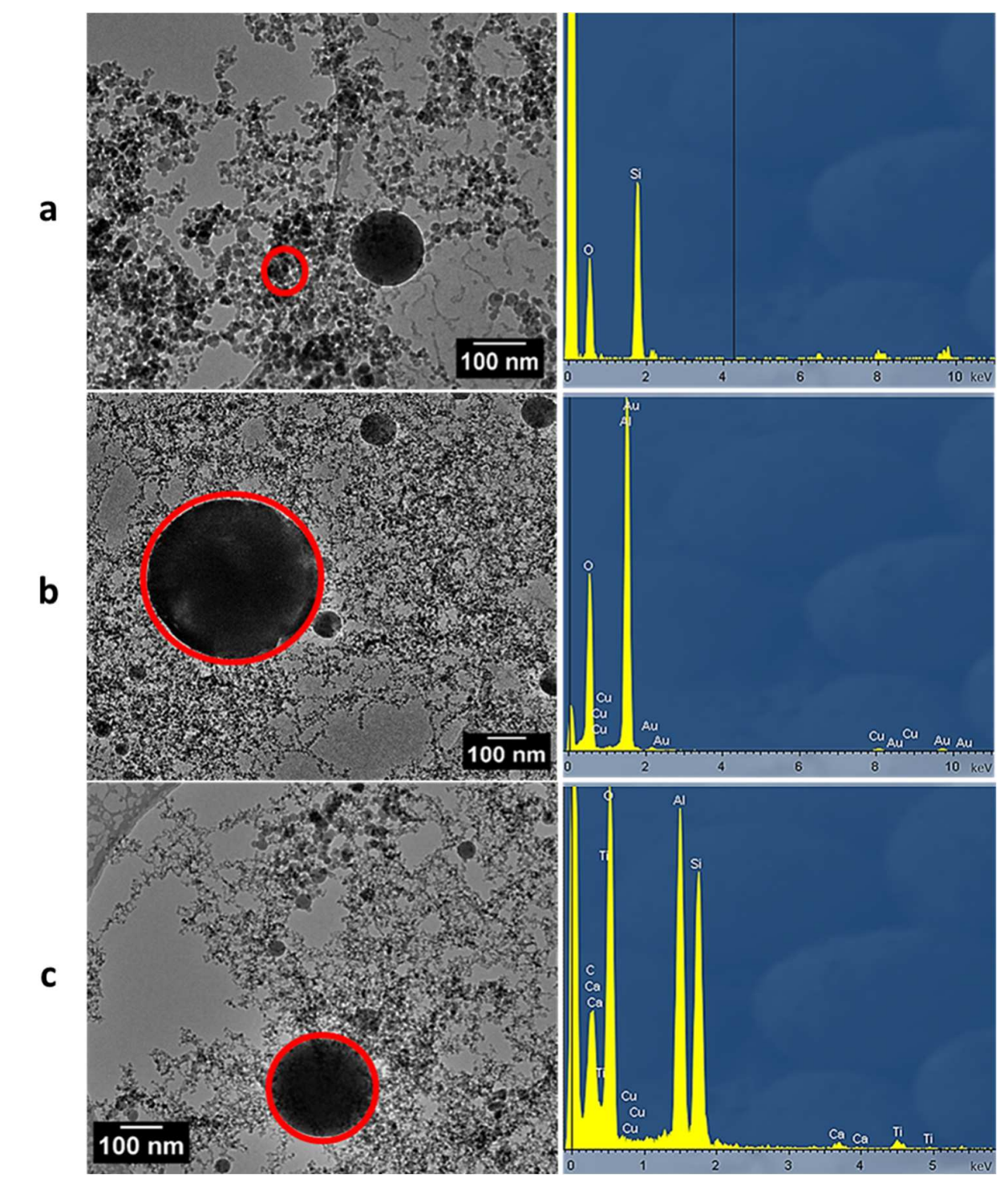

Figure 7. TEM images (left) and EDX spectra (right) of particles released during ablation under high energy settings, sourcing from: UPG (a), UAW (b), UBW (c) tiles

NPs formed during high energy ablation conditions were collected on TEM grids (Fig. 7). Particles released during the ablation of the UPG tiles were mainly consisting of silica (Fig. 8a), while the coarser spherical particles had similar composition to the tile (Table S1 in Supplementary material). The silica content of the UPG tiles was much higher than that of alumina (Table S1) and porcelain tiles have typically free silica, whilst alumina is combined with other compounds mainly forming mullite and abundant in vitreous silica phases (Sánchez et al., 2010; Sanchez, Orts, Garcia-Ten, \& Cantavella, 2001). Thereafter, silica rich vapours formed and condensed, promoting silica to emerge as the phase that dominated particle nucleation during UPG processing. Furthermore, oxides lose oxygen at high melting temperatures, consequently they 
become reduced and may decompose partially, which is also the case for silica where the suboxide $\left(\mathrm{SiO}_{x}\right)$ forms upon melting and reacts in air to form nanosized $\mathrm{SiO}_{2}$ (Fricke-Begemann, Meinertz, Weichenhain-Schriever, \& Ihlemann, 2014; Saxena, Agarwal, \& Kanjilal, 2011; Slaoui, Fogarassy, Fuchs, \& Siffert, 1992; Zhang, Lifshitz, \& Lee, 2003). Two types of alumina particles can be seen in Fig. $7 \mathrm{~b}$ : NPs originating from nucleation $(\mathrm{Dp}<10 \mathrm{~nm})$, and larger spherical particles from the droplets of molten material. Similar results were obtained for UBW tiles (Fig. 7c).

To conclude, even though the two porcelain tiles (UPG and UBW) had similar chemical composition (Table S1), differences in their NP emissions were observed. Specifically, $\mathrm{SiO}_{2} \mathrm{NPs}$ were formed and released in the case of UPG but not from the UBW tiles. This may be explained by the fact that the two porcelain tiles had different microstructures (Fig. S3 in Supplementary material). While the surface of the UPG tile shows agglomerates of grains in a vitreous (amorphous) matrix, the UBW tiles exhibit a more homogenous surface. Based on the above, it was interpreted that as the laser moved onto the surface of the UPG tile it would have melted and evaporated the different components, and consequently released species with different chemical composition than the matrix. Conversely, in the case of UBW tile all of the species emitted - and thus NPs - had the same chemical composition.

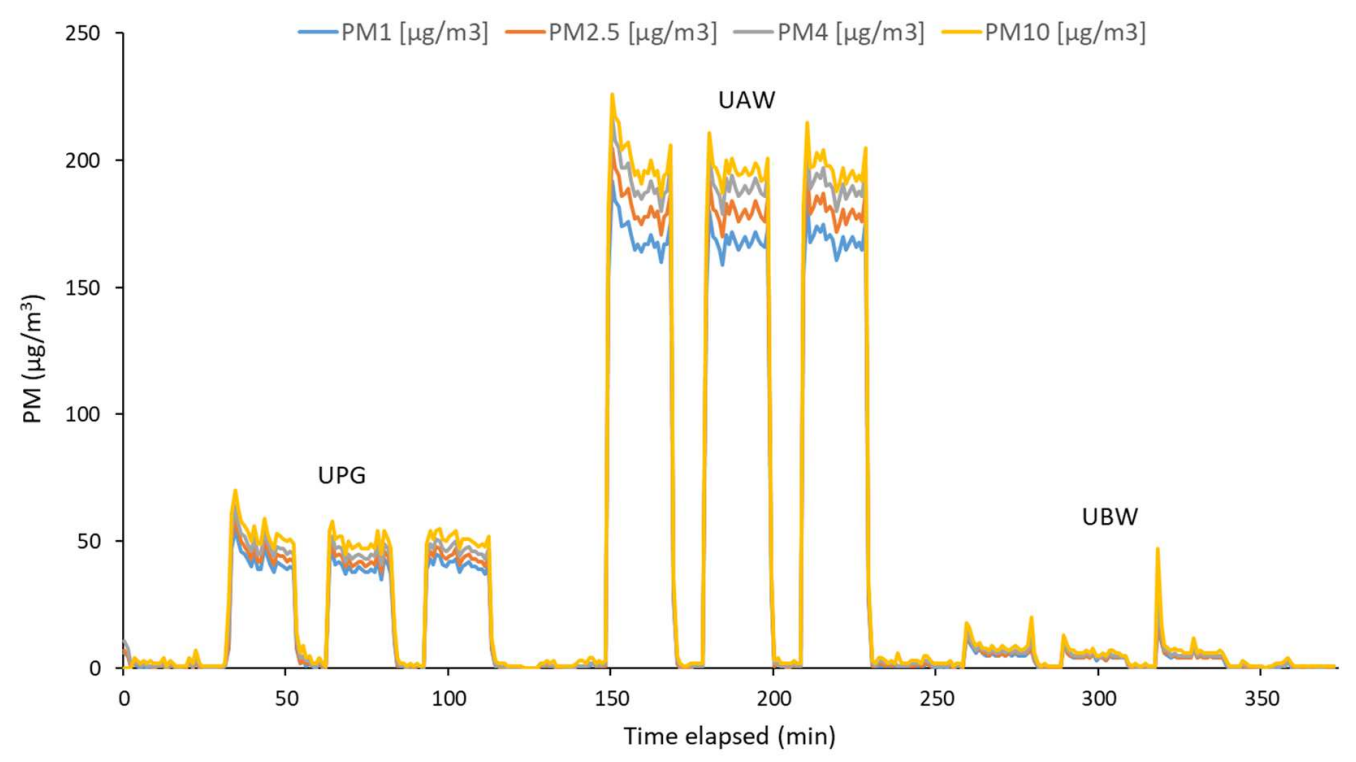

Figure 8. Particle mass concentrations during ablation with the near-IR laser under high energy settings

Particle mass concentrations are shown in Fig. 8, where $\mathrm{PM}_{2.5}$ emissions from UPG tiles (44 $\mu \mathrm{g} / \mathrm{m}^{3}$ ) were higher by a factor of 3 when compared to the low energy settings (Table 3 ). Hence, higher energy laser processing results in increased particle mass as well as number concentrations. The situation was different for UBW tiles, where a reduction was observed for particle mass concentrations, and $\mathrm{PM}_{2.5}$ values $\left(5.8 \mu \mathrm{g} / \mathrm{m}^{3}\right)$ decreased by a factor of two when compared to the low energy settings (Table 3). The $\mathrm{PM}_{1} / \mathrm{PM}_{10}$ ratio also decreased to $64 \%$, indicating a relatively higher contribution of coarser particles to emissions in particle mass. Due to the high temperatures achieved with the laser different chemical reactions and transformations 
were induced: the porous UBW tiles released nanosized particles from the homogenous melt, while in the case of dense porcelain tiles (UPG) thermal shock results in ejection of grains due to differences in thermal expansion coefficients (Lahoz et al., 2011; Pascual-Cosp et al., 2002, 2001). Therefore, the UPG released more particle mass than the UBW and these results are also in agreement with those obtained for particle number concentrations (Fig. 2).

Finally, particle mass concentrations for UAW tiles were similar under low and high energy settings, as was also the $\mathrm{PM}_{1} / \mathrm{PM}_{10}$ ratio (86\%). The relative shift in particle size distribution observed for NPs emitted during ablation of this kind of tile did not have an impact on particle mass concentrations, given that the major concentration of particles monitored had diameters 3$100 \mathrm{~nm}$.

\subsection{Mid-IR laser}

Particle number concentrations emitted from the UPG tiles (Fig. 9) were slightly lower $\left(2.37^{\star} 10^{5}\right.$ $/ \mathrm{cm}^{3}$ ) when compared to the $\mathrm{n}$-IR laser (high energy, $4.54^{*} 10^{5} / \mathrm{cm}^{3}$ ), but still in the same order of magnitude. However, particle emissions in the range 3-100 nm (Figure 10) were low and closer $\left(1000 / \mathrm{cm}^{3}\right)$ to the instrument's detection limit than for other types of tiles, which might explain the irregular pattern observed (Figure 10, top). This might also be explained by the fact that mechanisms which would have formed nanoparticles (e.g. nucleation) were minor contributors to the emissions. Particle number concentrations in the range 3-100 nm were the lowest of all the cases studied and mean particle diameter in the range $10-700 \mathrm{~nm}$ was larger (160 nm, Table 4) than in the case of the near-IR laser. Thus, the dominant ablation mechanism for this kind of tile was attributed to grain ejection due to shockwaves, which would have released small numbers of coarser particles (Figures 10 and 12).

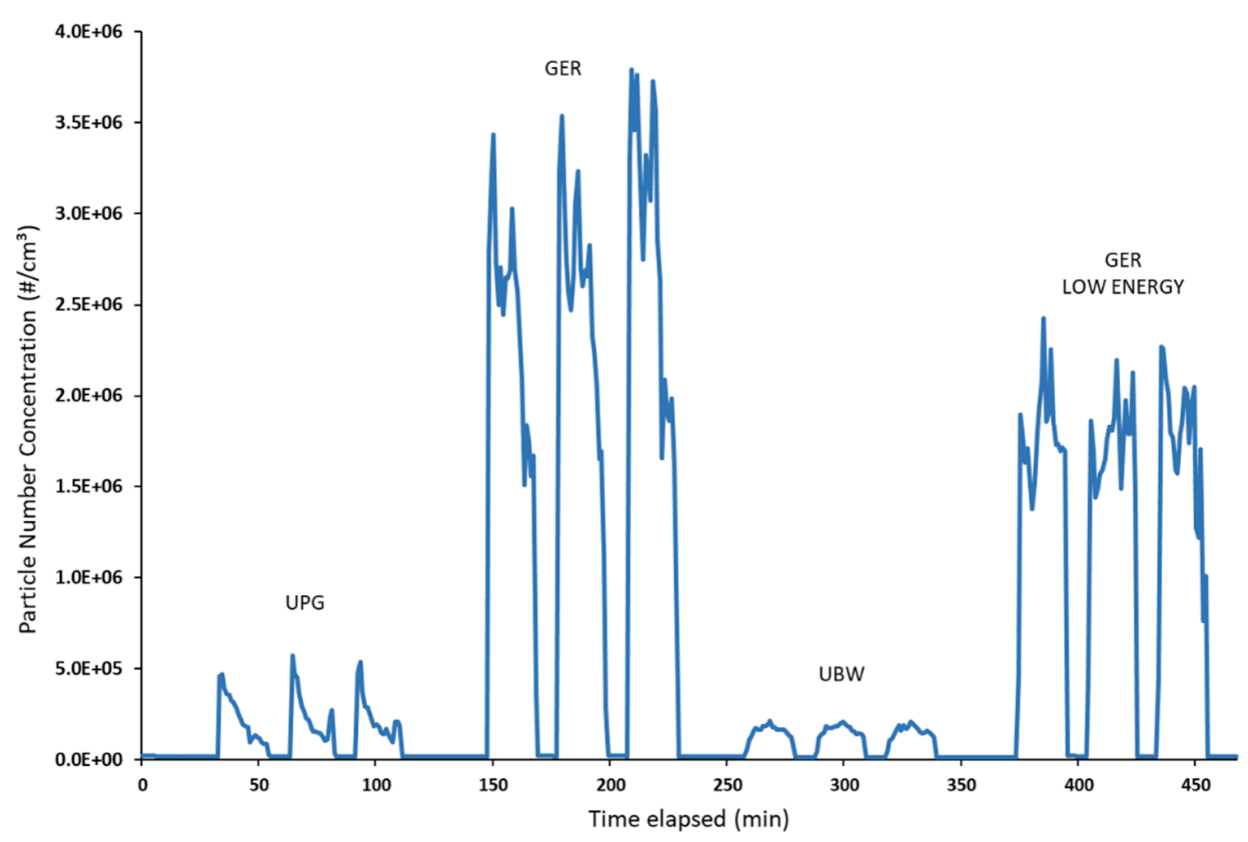

Figure 9. Particle number concentrations (size range $4 \mathrm{~nm}-3 \mu \mathrm{m}$ ) during ablation of the different types of tiles with the md-IR laser 
In the case of UBW tiles, particle number concentrations increased from the $\mathrm{n}$-IR (high energy) to the mid-IR laser ablation (from $6.9^{*} 10^{4} / \mathrm{cm}^{3}$ to $1.59^{*} 10^{5} / \mathrm{cm}^{3}$; Table 3 and 4 respectively). However, the particle size distribution in the range $3-100 \mathrm{~nm}$ (Fig. 10) showed a very different pattern suggesting different ablation mechanisms. In the $\mathrm{n}$-IR case (Fig. 6) nucleation was the dominant mechanism with a minor contribution of melting, while in the case of mid-IR laser there was a more uniform release of NPs in all size bins. Thus, no dominant NP formation mechanism was identified, it can rather be interpreted that a combination of mechanisms was contributing similarly to the emissions in this specific size range $(3-100 \mathrm{~nm})$.
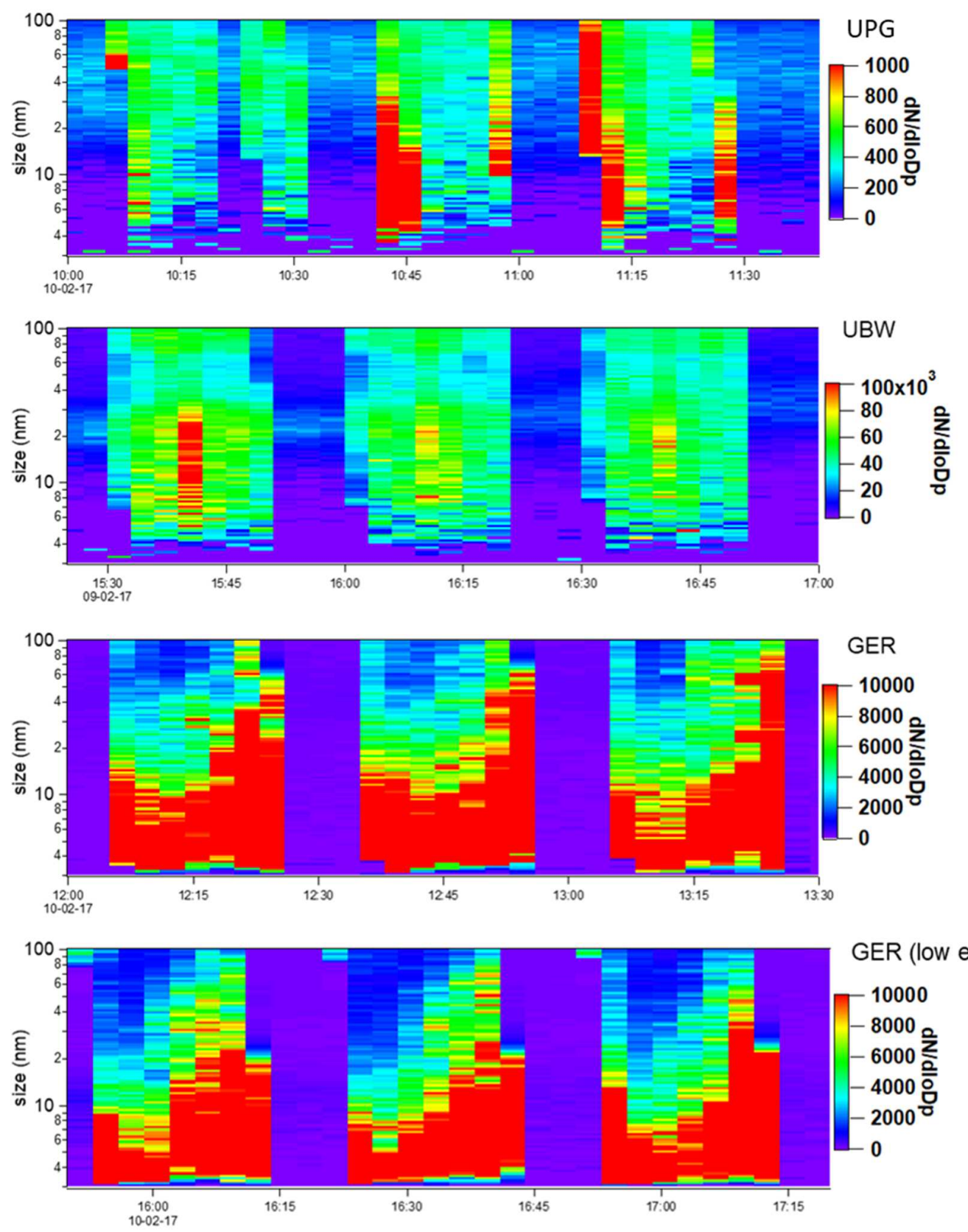

Figure 10. Size distribution (3-100 nm) of particles emitted during ablation with the mid-IR laser 
Finally, particle emissions during ablation of the GER tiles were noticeable due to the unexpectedly high concentrations monitored $\left(2.6^{*} 10^{6} / \mathrm{cm}^{3}\right.$; Fig. 9). GER was ablated under two energy settings aiming to understand these emissions. The high particle number concentrations were almost one order of magnitude higher than for any of the other materials, even under the lower energy settings. The particle size distribution patterns $(3-100 \mathrm{~nm}$; Fig. 10) were very similar and reproducible for both energy settings, and dominated by NPs $<20 \mathrm{~nm}$ with an increasing contribution of $<40 \mathrm{~nm}$ NPs as the tile was being ablated. This would suggest a strong influence of nucleation and new particle formation processes. In addition, during ablation it is expected that the glaze, the main difference with the previous materials, would have molten and generated the ejection of droplets of different sizes in this case mainly $>100 \mathrm{~nm}$. Thus, these particles would have been outside the scanning range of the SMPS system used in this work, but not of the CPC

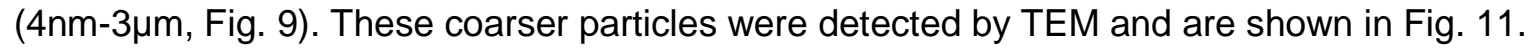

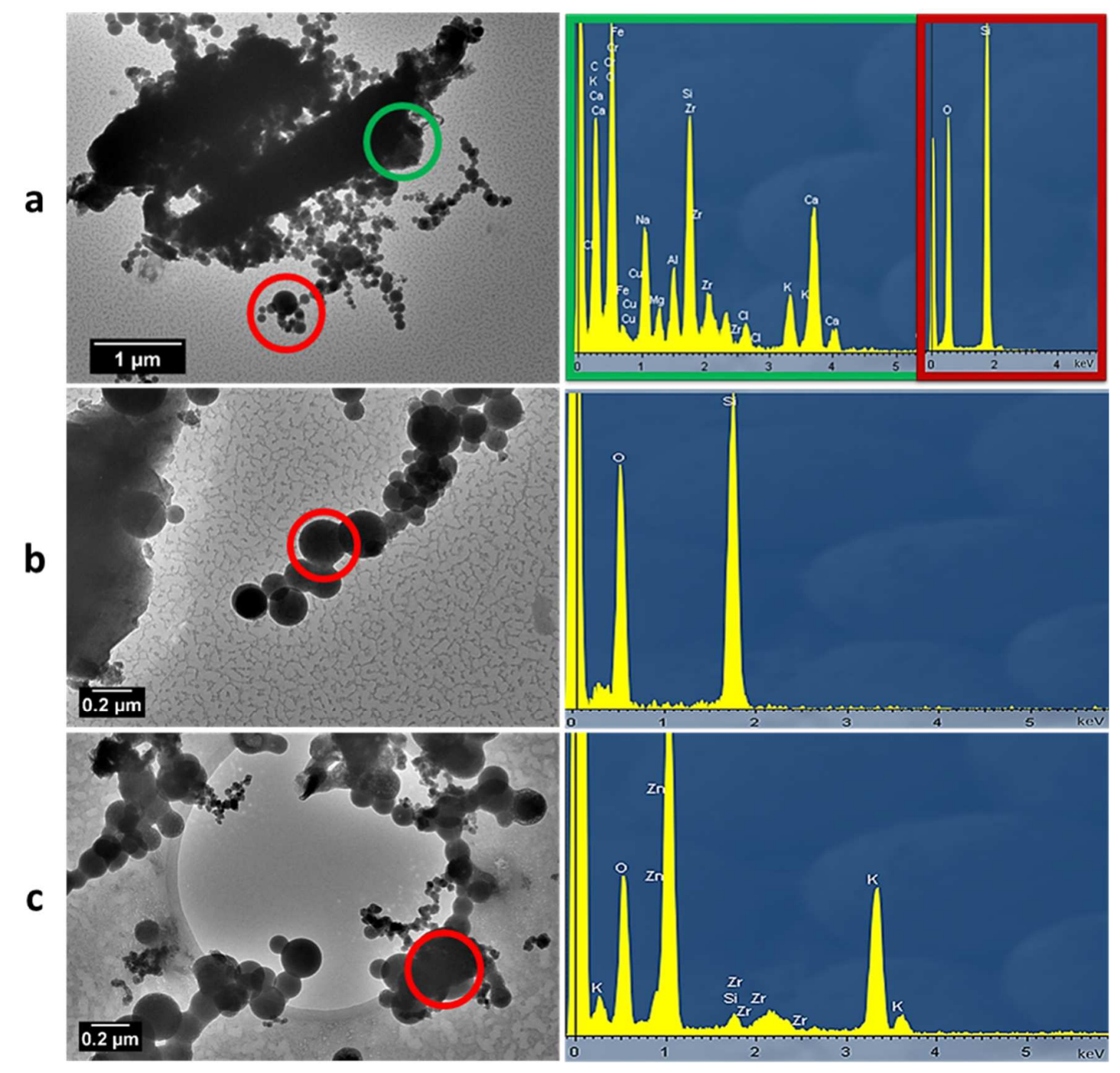

Figure 11. TEM images (left) and EDX spectra (right) of particles released during ablation using mid-IR laser, sourcing from UPG (a), UBW (b), GER (c) tiles 
TEM images of particles emitted during ablation with the mid-IR laser are shown in Fig. 11. As evidenced by the shape and size of the particles emitted (Fig. 11a), coarse grains of UPG tiles were released due to the mechanical shockwave mechanism. EDX analysis of the smaller spherical particles (Fig. 11a marked in red) showed that they consist of $\mathrm{SiO}_{2}$, probably originating from the evaporation of silica, as was described in section 3.1.2. The case is similar for UBW tiles (Fig. 11b), where spherical particles were also present. The formation of silica particles during the ablation of the UBW occurred during irradiation with the mid-IR laser, while this effect was not observed with the near-IR laser. The higher energy transmitted to the surface of the same tiles, as well as the different wavelength of the radiation, may create a more extensive heat-affected zone and modify the formation and release mechanisms, a fact that can be observed in the shape and size of the particles emitted (Fig. 11). Finally, different types of particles were identified during ablation of GER tiles (Fig. 11c): spherical and relatively coarser particles (>200 nm) originating from melt ejection, while irregular aggregates and NPs $<20 \mathrm{~nm}$ are attributed to nucleation processes. The majority of the particles consisted mainly of zinc oxide, which is in the glassy phase of the glaze (Aparici, Moreno, Escardino, Amoros, \& Mestre, 1994).

High particle mass concentrations (up to $\mathrm{PM}_{2.5} 11900 \mu \mathrm{g} / \mathrm{m}^{3}$ ) with irregular emission patterns were recorded for the GER tiles, which varied as a function of the energy settings (Figure 12). The shockwave mechanism was attributed as the main contributor to these emissions. For UBW tiles mass concentrations were higher by 2 orders of magnitude (Table 4) than those monitored with the near-IR laser, while only by a factor of 2 in terms of particle number concentration. This fact confirms the change in the dominant emission mechanism from nucleation and droplets expulsion with the near-IR laser, to the mechanical shockwave with the mid-IR laser. For the UPG tiles, particle number concentrations decreased by a factor of 2 while particle mass concentrations increased by a factor of 4 with the mid-IR laser when compared to values obtained with the $\mathrm{n}$-IR laser (Tables 3 and 4). The above offer a validation on the relevance of the mechanical shockwave mechanism with mid-IR PLA of ceramic tiles.

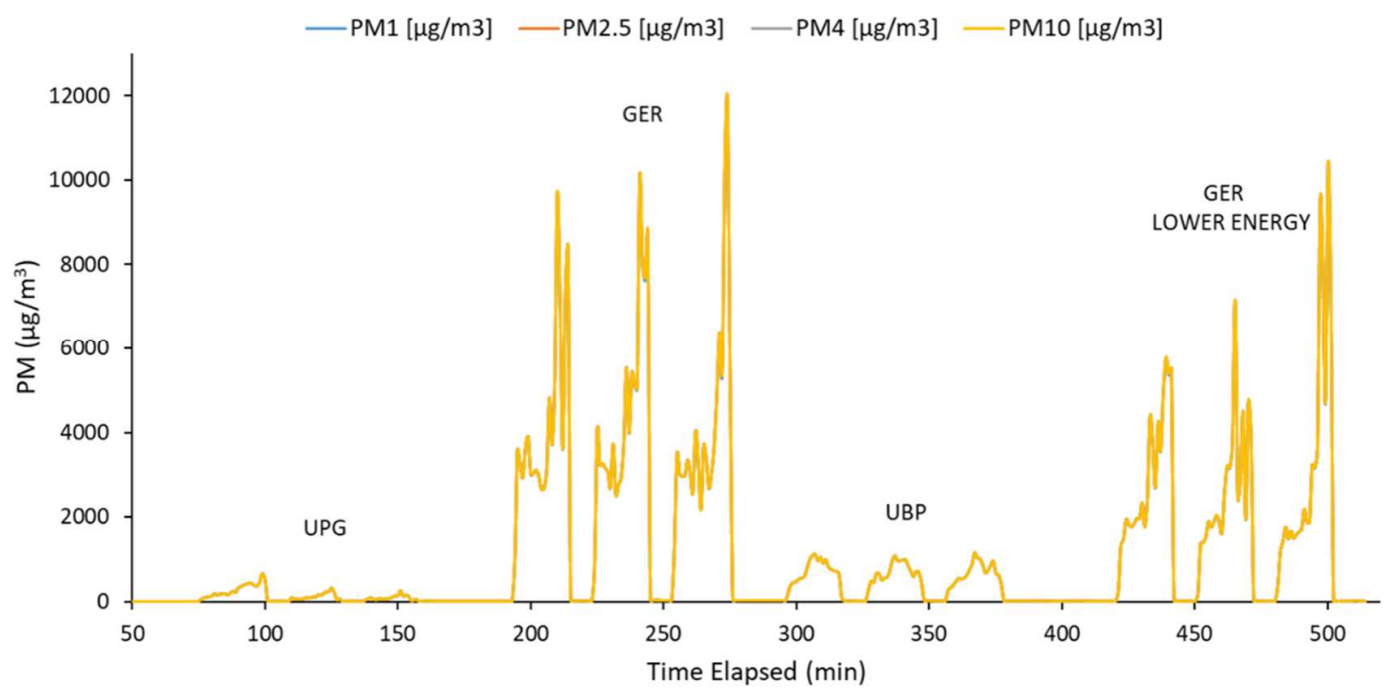

Figure 12. Particle mass concentrations of the emissions, for the different tiles and energy settings during ablation with the mid-IR laser 


\section{Discussion}

Particle formation mechanisms during PLA of ceramic tiles were proposed by correlating measured particle number concentrations and size distributions with ablation phenomena described in the ceramic literature. Parameters found to influence particle emissions were laser type and energy settings, as well as the type of tile and their surface characteristics (chemical and physical). The mechanisms which contributed to particle emissions in this study are summarised in Figure 13, including the relationship between the dominant particle emission mechanisms and the types of laser used. Based on the results presented in the previous section, particle nucleation was the dominant mechanism in terms of particle number emissions in the size range 3-20 nm, while high emissions in terms of particle mass concentrations were attributed to mechanical shockwaves (>100 nm). Conversely, tile melting contributed to particle mass and number emissions given that it may generate droplets with a wide range of particle diameters (with a mean diameter around $40 \mathrm{~nm}$ ). It should be noted that the melting mode comprises also agglomerates and aggregates of smaller particles, as evidenced in Figures 4 and 11. Due to high surface energy the smaller nanoparticles have a strong tendency to rapidly form agglomerates in order to reach a more stable state (Max L. Eggersdorfer et al., 2012; Polte, 2015). Agglomerates can have a wide range of sizes depending on the primary size of the particles as well as the number of clustered particles. Further research is necessary to distinguish between the contributions solely from the melting mechanism and from nanoparticle agglomeration. Finally, with regard to the influence of the type of laser, nucleation and melting were observed with the near-IR laser whereas melting and mechanical shockwaves were more present in the case of the mid-IR laser.

Table 5 links the particle emission characteristics observed with the emission mechanisms proposed, for all the combinations of tiles and laser parameters. For the near-IR laser, total particle number concentrations (measured with CPC) increased by one order of magnitude (104 to $10^{5} / \mathrm{cm}^{3}$, and $10^{5}$ to $10^{6} / \mathrm{cm}^{3}$ ) with increasing energy (from low to high) for two of the three tiles (UPG and UAW, respectively), while the UBW tile showed a slightly different pattern with similar total particle emissions for both energy settings $\left(10^{4} / \mathrm{cm}^{3}\right)$. When looking strictly at the $3-100 \mathrm{~nm}$ size range (measured with SMPS), particle number concentrations did show an increasing trend for all of the materials with increasing energy input. Mean particle diameter increased for UPG and UAW from the low to the high energy inputs, while the UBW tiles showed again a different trend (with decreasing particle diameter). Furthermore, for particle mass concentrations $\left(\mathrm{PM}_{2.5}\right.$ in Table 5) emissions from UPG and UAW tiles with the n-IR laser increased from lower to higher energies, while they decreased for the UBW tiles (in accordance with the dominant mechanism). The same was observed regarding the dominant mechanisms proposed for particle emission: the UPG and UAW tiles followed an evolution, from low to high energy inputs, from nucleationdominated emissions to melting, and finally mechanical shockwave (Figure 13). Conversely, the UBW tiles showed a prevalence of melting with low energy inputs, and of nucleation for the high energy settings, which suggests that higher energy inputs were necessary to generate the adequate conditions for nucleation, for this type of tiles.

Given that the UPG and UBW tiles have a similar chemical composition (Table 1), these results suggest that tile physical properties such as microstructure (i.e. crystallinity, Figure S6 in 
Supplementary material), optical properties (colour) or porosity play a relevant role in particle emissions. Hence, it may be concluded that the type of material, as well as the laser parameters, affect particle emissions during PLA of ceramic tiles. The different patterns observed for the UBW tiles when compared to the UPG and UAW tiles require further research, in order to understand the differences detected. However, it should be noted that UBW is typically an intermediate product in the ceramic industry, and not as relevant from a particle emission and workplace exposure perspective as the other materials, much more generally used in the industry.

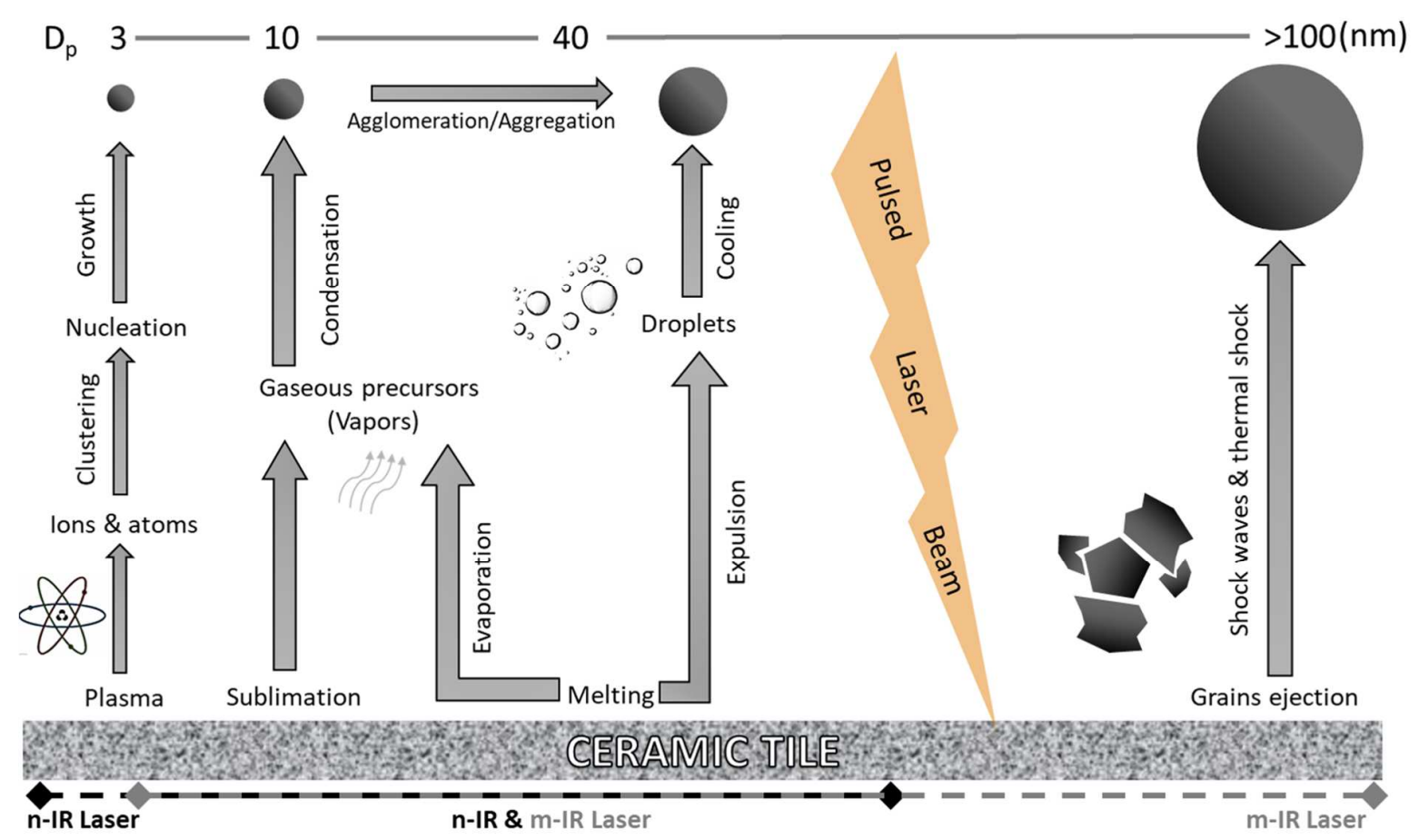

Figure 13. Schematic illustration of UFP formation and release mechanisms during PLA of ceramic tiles

\section{Conclusions}

This work presents an interdisciplinary study, which aims to establish a connection between aerosol research, laser ablation and ceramic technology, with potential implications for human health. NP emissions were monitored during pulsed laser ablation (PLA) of ceramic tiles with the aim to understand the mechanisms behind particle formation and release. The assessment of particle number concentrations and size distributions evidenced that particle formation was directly connected with ablation phenomena. Four different types of tiles (unglazed porcelain, unglazed alumina, unglazed biscuit porcelain and glazed earthenware) and two lasers (near-IR and mid-IR) were used. Irrespective of the combination of laser and tile used, high concentrations of NPs were released during PLA of ceramic tiles. The ceramic tile composition, physicochemical properties, and surface microstructure are parameters which affect particle release during PLA. In terms of particle number, emissions were higher during the ablation of unglazed alumina (UAW) 
and glazed earthenware (GER). $\mathrm{SiO}_{2}$ and $\mathrm{Al}_{2} \mathrm{O}_{3}$ particles $(>10 \mathrm{~nm}$ ) were formed through different nucleation pathways during ablation of the ceramic tiles.

Although a combination of mechanisms was seen to contribute to particle number emissions, the dominant ones were nucleation and melting with the near-IR laser, whereas they were melting and mechanical shockwaves for the mid-IR laser. Melting and the subsequent ejection of droplets in the range 40-700 nm were found to have a significant contribution in terms of particle number concentration. Nucleation generated particles $<20 \mathrm{~nm}$, and mechanical shockwaves released particles $>100 \mathrm{~nm}$. Thus, the ablation of tiles for which the dominant mechanism was nucleation resulted in high particle number concentrations, whereas for tiles dominated by mechanical shockwaves high particle mass concentrations were monitored. These results are potentially relevant from the point of view of exposure mitigation strategies in industrial facilities where PLA is carried out. The localized extraction system implemented in the scenarios assessed proved to be an efficient mitigation measure, as it prevented particle release to the worker area.

\section{Acknowledgements}

The authors kindly acknowledge Mr. Carlos Borrell and Mr. Carlos Estepa for their help during the experimental work and Dr Natalia Moreno for the XRD measurements. The current work was carried out in the framework of the CERASAFE project (www.cerasafe.eu), with the support of SIINN ERA-NET (project id: 16), and is funded by the Spanish MINECO (PCIN-2015-173-C0201). Partial support from project MAT2016-79866-R (AEI/FEDER, UE) is acknowledged. 
Table 3. Particle concentrations and mean diameters monitored during ablation with the near-IR laser.

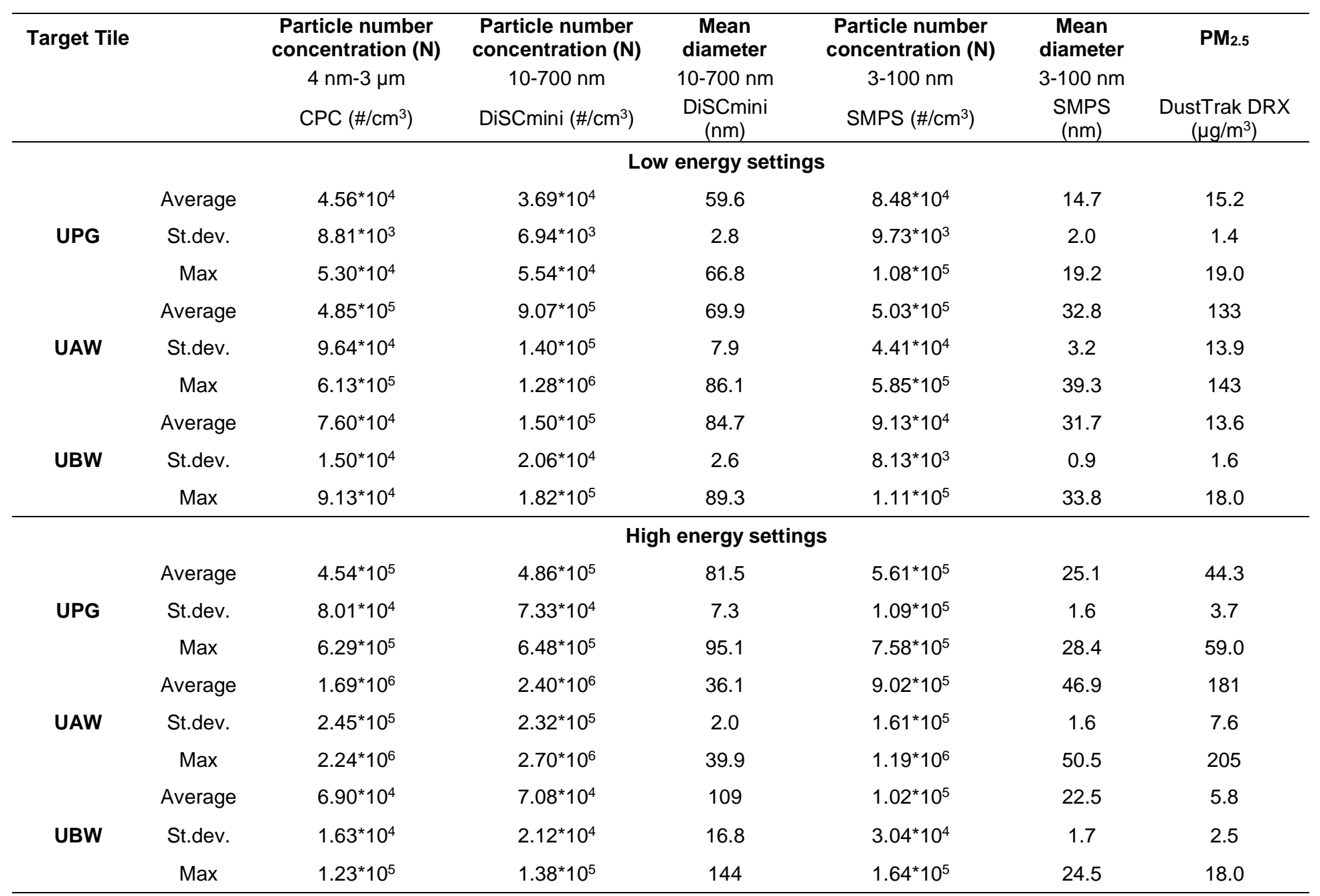


Table 4. Particle concentrations and mean diameters monitored during ablation with the mid-IR laser

\begin{tabular}{|c|c|c|c|c|c|c|c|}
\hline Target Tile & & $\begin{array}{c}\text { Particle number } \\
\text { concentration (N) } \\
4 \mathrm{~nm}-3 \mu \mathrm{m} \\
\mathrm{CPC}\left(\# / \mathrm{cm}^{3}\right)\end{array}$ & $\begin{array}{c}\text { Particle number } \\
\text { concentration (N) } \\
10-700 \mathrm{~nm} \\
\text { DiSCmini }\left(\# / \mathrm{cm}^{3}\right)\end{array}$ & $\begin{array}{c}\text { Mean } \\
\text { diameter } \\
10-700 \\
\mathrm{~nm} \\
\text { DiSCmini } \\
(\mathrm{nm}) \\
\end{array}$ & $\begin{array}{c}\text { Particle number } \\
\text { concentration (N) } \\
3-100 \mathrm{~nm} \\
\text { SMPS }\left(\# / \mathrm{cm}^{3}\right)\end{array}$ & $\begin{array}{c}\text { Mean } \\
\text { diameter } \\
3-100 \mathrm{~nm} \\
\text { SMPS } \\
(\mathrm{nm}) \\
\end{array}$ & $\begin{array}{c}\text { DustTrak DRX } \\
\left(\mu \mathrm{g} / \mathrm{m}^{3}\right)\end{array}$ \\
\hline \multirow{4}{*}{ UPG } & Average & $2.37^{*} 10^{5}$ & $1.70^{*} 10^{5}$ & 97.4 & $4.94^{*} 10^{4}$ & 29.4 & 171 \\
\hline & St.dev. & $1.24^{*} 10^{5}$ & $1.16^{*} 10^{5}$ & 35.6 & $3.22 * 10^{4}$ & 5.9 & 134 \\
\hline & Max & $5.73^{*} 10^{5}$ & $5.13^{*} 10^{5}$ & 187 & $1.49^{*} 10^{5}$ & 38.6 & 674 \\
\hline & Average & $1.59 * 10^{5}$ & $1.62 * 10^{5}$ & 96.7 & $6.64^{*} 10^{4}$ & 28.1 & 727 \\
\hline \multirow[t]{3}{*}{ UBW } & St.dev. & $3.29 * 10^{4}$ & $3.07^{*} 10^{4}$ & 8.2 & $1.28^{*} 10^{4}$ & 2.1 & 231 \\
\hline & Max & $2.14^{*} 10^{5}$ & $2.20^{*} 10^{5}$ & 110 & $1.03 * 10^{5}$ & 32.7 & 1160 \\
\hline & Average & $2.62^{*} 10^{6}$ & $1.47^{*} 10^{6}$ & 48.5 & $2.03^{*} 10^{6}$ & 12.8 & 4450 \\
\hline \multirow[t]{2}{*}{ GER } & St.dev. & $6.48^{*} 10^{5}$ & $5.58^{*} 10^{5}$ & 7.5 & $1.96^{*} 10^{6}$ & 3.9 & 2259 \\
\hline & $\operatorname{Max}$ & $3.79 * 10^{6}$ & $2.70^{*} 10^{6}$ & 61.5 & $6.76^{*} 10^{6}$ & 18.8 & 11900 \\
\hline \multirow{3}{*}{$\begin{array}{c}\text { GER (low } \\
\text { energy } \\
\text { settings) }\end{array}$} & Average & $1.76^{*} 10^{6}$ & $8.39 * 10^{5}$ & 68.1 & $2.63^{*} 10^{6}$ & 12.4 & 3119 \\
\hline & St.dev. & $2.97^{\star} 10^{5}$ & $1.56^{*} 10^{5}$ & 10.1 & $5.64^{*} 10^{6}$ & 4.4 & 2062 \\
\hline & Max & $2.43^{\star} 10^{6}$ & $1.45^{*} 10^{6}$ & 97.1 & $2.45^{*} 10^{7}$ & 18.9 & 10400 \\
\hline
\end{tabular}


Table 5. Emission mechanisms identified and their characteristics during PLA of different ceramic tiles

\begin{tabular}{|c|c|c|c|c|c|}
\hline $\begin{array}{l}\text { Energy } \\
\text { Settings }\end{array}$ & Emission characteristics & UPG & UAW & UBW & GER \\
\hline \multicolumn{6}{|c|}{ Near-IR Laser } \\
\hline \multirow{5}{*}{ Low } & $\mathrm{N}_{p}-\mathrm{CPC}\left(\# / \mathrm{cm}^{3}\right)$ & $4.6^{*} 10^{4}$ & $4.9^{*} 10^{5}$ & $7.6^{*} 10^{4}$ & - \\
\hline & Mean $D_{p}-$ SMPS (nm) & 14.7 & 32.8 & 31.7 & - \\
\hline & $\mathrm{N}_{p}-\operatorname{SMPS}\left(\# / \mathrm{cm}^{3}\right)$ & $8.5^{\star} 10^{4}$ & $5.0^{*} 10^{5}$ & $9.1 * 10^{4}$ & - \\
\hline & $\mathrm{PM}_{2.5}\left(\mu \mathrm{g} / \mathrm{m}^{3}\right)$ & 15.2 & 133 & 13.6 & - \\
\hline & Dominant mechanism & Nucleation & Nucleation, Melting & Melting & - \\
\hline \multirow{5}{*}{ High } & $\mathrm{N} p-\mathrm{CPC}\left(\# / \mathrm{cm}^{3}\right)$ & $4.5^{\star} 10^{5}$ & $1.7^{*} 10^{6}$ & $6.9^{*} 10^{4}$ & - \\
\hline & Mean $D_{p}-$ SMPS (nm) & 25.1 & 46.9 & 22.5 & - \\
\hline & $\mathrm{N}_{\mathrm{p}}-\mathrm{SMPS}\left(\# / \mathrm{cm}^{3}\right)$ & $5.6^{*} 10^{5}$ & $9.0^{*} 10^{5}$ & $1.0^{*} 10^{5}$ & - \\
\hline & $\mathrm{PM}_{2.5}\left(\mu \mathrm{g} / \mathrm{m}^{3}\right)$ & 44.3 & 181 & 5.8 & - \\
\hline & Dominant mechanism & Nucleation, Melting & Nucleation, Melting & Nucleation & - \\
\hline \multicolumn{6}{|c|}{ Mid-IR Laser } \\
\hline \multirow{5}{*}{ Standard } & $\mathrm{N}_{\mathrm{p}}-\mathrm{CPC}\left(\# / \mathrm{cm}^{3}\right)$ & $2.4^{*} 10^{5}$ & - & $1.6^{*} 10^{5}$ & $2.6^{*} 10^{6}$ \\
\hline & Mean $D_{p}-$ SMPS (nm) & 29.4 & - & 28.1 & 12.8 \\
\hline & $\mathrm{N}_{\mathrm{p}}-\mathrm{SMPS}\left(\# / \mathrm{cm}^{3}\right)$ & $4.9^{*} 10^{4}$ & - & $6.6^{*} 10^{4}$ & $2.0^{*} 10^{6}$ \\
\hline & $\mathrm{PM}_{2.5}\left(\mu \mathrm{g} / \mathrm{m}^{3}\right)$ & 171 & - & 727 & 44450 \\
\hline & Dominant mechanism & Shockwave & - & Combined $^{a}$ & Combined $^{a}$ \\
\hline \multirow{5}{*}{ Low } & $\mathrm{N}_{p}-\mathrm{CPC}\left(\# / \mathrm{cm}^{3}\right)$ & - & - & - & $1.8^{*} 10^{6}$ \\
\hline & Mean $D_{p}-S M P S(n m)$ & - & - & - & 12.4 \\
\hline & $\mathrm{N}_{p}-\mathrm{SMPS}\left(\# / \mathrm{cm}^{3}\right)$ & - & - & - & $2.6^{*} 10^{6}$ \\
\hline & $\mathrm{PM}_{2.5}\left(\mu \mathrm{g} / \mathrm{m}^{3}\right)$ & - & - & - & 3119 \\
\hline & Dominant mechanism & - & - & - & Combined $^{a}$ \\
\hline
\end{tabular}

${ }^{a}$ Combined contribution from nucleation, melting and shockwaves. 


\section{REFERENCES}

Andreeta, M. R. B., Cunha, L. S., Vales, L. F., Caraschi, L. C., \& Jasinevicius, R. G. (2011). Bidimensional codes recorded on an oxide glass surface using a continuous wave $\mathrm{CO} 2$ laser. Journal of Micromechanics and Microengineering, 21(2), 025004. https://doi.org/10.1088/0960$1317 / 21 / 2 / 025004$

Aparici, J., Moreno, A., Escardino, A., Amoros, J. L., \& Mestre, S. (1994). Study of Opacification in Zirconium Ceramic Glazes Used in Single-Fired Wall Tile Manufacture. In Study of Opacification in Zirconium Ceramic Glazes Used in Single-Fired Wall Tile Manufacture (pp. 35-45). Castellon de la plana, Spain: QUALICER 94.

Asbach, C., Kaminski, H., Lamboy, Y., Schneiderwind, U., Fierz, M., \& Todea, A. M. (2016). Silicone sampling tubes can cause drastic artifacts in measurements with aerosol instrumentation based on unipolar diffusion charging. Aerosol Science and Technology, 50(12), 1375-1384. https://doi.org/10.1080/02786826.2016.1241858

Carty, W. M., \& Senapati, U. (1998). Porcelain - Raw materials, processing, phase evolution, and mechanical behavior. Journal of the American Ceramic Society, 81(1), 3-20. https://doi.org/10.1111/j.1151-2916.1998.tb02290.x

Curwin, B., \& Bertke, S. (2011). Exposure characterization of metal oxide nanoparticles in the workplace. Journal of Occupational and Environmental Hygiene, 8(10), 580-587. https://doi.org/10.1080/15459624.2011.613348

Czotscher, T., \& Vollertsen, F. (2016). Analysis of melting and melt expulsion during nanosecond pulsed laser ablation. Physics Procedia, 83, 53-61. https://doi.org/10.1016/j.phpro.2016.08.007

Demou, E., Peter, P., \& Hellweg, S. (2008). Exposure to manufactured nanostructured particles in an industrial pilot plant. Annals of Occupational Hygiene, 52(8), 695-706. https://doi.org/10.1093/annhyg/men058

Eggersdorfer, M. L., Kadau, D., Herrmann, H. J., \& Pratsinis, S. E. (2012). Aggregate morphology evolution by sintering: Number and diameter of primary particles. Journal of Aerosol Science, 46, 719. https://doi.org/10.1016/j.jaerosci.2011.11.005

Eggersdorfer, M. L., \& Pratsinis, S. E. (2014). Agglomerates and aggregates of nanoparticles made in the gas phase. Advanced Powder Technology, 25(1), 71-90. https://doi.org/10.1016/j.apt.2013.10.010

Fonseca, A. S., Maragkidou, A., Viana, M., Querol, X., Hämeri, K., de Francisco, I., ... de la Fuente, G. F. (2016). Process-generated nanoparticles from ceramic tile sintering: Emissions, exposure and environmental release. Science of the Total Environment, 565, 922-932. https://doi.org/10.1016/j.scitotenv.2016.01.106

Fonseca, A. S., Viana, M., Querol, X., Moreno, N., de Francisco, I., Estepa, C., \& de la Fuente, G. F. (2015). Ultrafine and nanoparticle formation and emission mechanisms during laser processing of ceramic materials. Journal of Aerosol Science, 88, 48-57. https://doi.org/10.1016/j.jaerosci.2015.05.013

Fonseca, A. S., Viitanen, A. K., Koivisto, A. J., Kangas, A., Huhtiniemi, M., Hussein, T., ... Hameri, K. (2014). Characterization of exposure to carbon nanotubes in an industrial setting. Annals of Occupational Hygiene, 59(5), 586-599. https://doi.org/10.1093/annhyg/meu110

Fricke-Begemann, T., Meinertz, J., Weichenhain-Schriever, R., \& Ihlemann, J. (2014). Silicon suboxide (SiOx): laser processing and applications. Applied Physics A: Materials Science and Processing, 117(1), 13-18. https://doi.org/10.1007/s00339-014-8236-3

Gandra, J., Miranda, R., Vilaa, P., Velhinho, A., \& Teixeira, J. P. (2011). Functionally graded materials produced by friction stir processing. Journal of Materials Processing Technology, 211(11), 16591668. https://doi.org/10.1016/j.jmatprotec.2011.04.016 
Gómez, V., Irusta, S., Balas, F., \& Santamaria, J. (2013). Intense generation of respirable metal nanoparticles from a low-power soldering unit. Journal of Hazardous Materials, 256-257, 84-89. https://doi.org/10.1016/j.jhazmat.2013.03.067

Hameri, K., Lahde, T., Hussein, T., Koivisto, J., \& Savolainen, K. (2009). Facing the key workplace challenge: Assessing and preventing exposure to nanoparticles at source. Inhalation Toxicology, 21, 17-24. https://doi.org/10.1080/08958370902942525

Heal, M. R., Kumar, P., \& Harrison, R. M. (2012). Particles, air quality, policy and health. Chemical Society Reviews, 41(19), 6606. https://doi.org/10.1039/c2cs35076a

International Organization for Standardization. (2012). International Organization for Standardization 13006: Ceramic tiles - Definitions, classification, characteristics and marking. USA: ISO.

Koch, W., \& Friedlander, S. K. (1989). The effect of particle coalescence on the surface area of a coagulating aerosol. Journal of Aerosol Science, 20(8), 891-894. https://doi.org/https://doi.org/10.1016/0021-8502(89)90719-2

Koivisto, A. J., Lyyränen, J., Auvinen, A., Vanhala, E., Hämeri, K., Tuomi, T., \& Jokiniemi, J. (2012). Industrial worker exposure to airborne particles during the packing of pigment and nanoscale titanium dioxide. Inhalation Toxicology, 24(12), 839-849. https://doi.org/10.3109/08958378.2012.724474

Lahoz, R., De La Fuente, G. F., Pedra, J. M., \& Carda, J. B. (2011). Laser engraving of ceramic tiles. International Journal of Applied Ceramic Technology, 8(5), 1208-1217. https://doi.org/10.1111/j.1744-7402.2010.02566.x

Lushnikov, A. A., Maksimenko, V. V, \& Pakhomov, A. V. (1989). Fractal aggregates from laser plasma. Journal of Aerosol Science, 20(8), 865-870. https://doi.org/10.1016/0021-8502(89)90713-1

Nedialkov, N. N., Atanasov, P. A., Sawczak, M., \& Sliwinski, G. (2003). Ablation of ceramics with ultraviolet, visible, and infrared nanosecond laser pulses. In Proc. SPIE 5120, XIV International Symposium on Gas Flow, Chemical Lasers, and High-Power Lasers (Vol. 5120, pp. 703-708). https://doi.org/10.1117/12.515847

Noël, S., Hermann, J., \& Itina, T. (2007). Investigation of nanoparticle generation during femtosecond laser ablation of metals. Applied Surface Science, 253(15), 6310-6315. https://doi.org/10.1016/j.apsusc.2007.01.081

Oberdörster, G. (2001). Pulmonary effects of inhaled ultrafine particles. International Archives of Occupational and Environmental Health, 74(1), 1-8. https://doi.org/10.1007/s004200000185

Pascual-Cosp, J., Ramírez del Valle, A. J., Garciá-Fortea, J., \& Sánchez-Soto, P. J. (2002). Laser cutting of high-vitrified ceramic materials: Development of a method using a Nd:YAG laser to avoid catastrophic breakdown. Materials Letters, 55(4), 274-280. https://doi.org/10.1016/S0167$577 \times(02) 00377-4$

Pascual-Cosp, J., Ramírez Del Valle, A. J., García Fortea, J., \& Sánchez Soto, P. J. (2001). Thermal evolution of a ceramic material processed using a Nd-YAG laser. Boletin de La Sociedad Espanola de Ceramica y Vidrio.

Pascual, A., Fortanet, E., Carda, J. B., Pavlov, R., Pedra, J. M., De La Fuente, G. F., ... Lahoz, R. (2005). Ceramic tile decoration by laser technology. In CFI Ceramic Forum International (Vol. 82). Castellon de la plana, Spain.

Pfefferkorn, F. E., Bello, D., Haddad, G., Park, J. Y., Powell, M., McCarthy, J., ... Hoover, M. D. (2009). Characterization of exposures to airborne nanoscale particles during friction stir welding of aluminum. Annals of Occupational Hygiene, 54(5), 486-503.

https://doi.org/10.1093/annhyg/meq037 
Phipps, C. (2007). Laser Ablation and its Applications. (E. W. T. Rhodes, E. B. a Adibi, T. Asakura, T. W. Hansch, T. Kamiya, F. Krausz, ... W. T. Rhodes, Eds.), Springer Series in Optical Sciences (Vol. 129). USA: Springer. https://doi.org/10.1007/978-0-387-30453-3

Polte, J. (2015). Fundamental growth principles of colloidal metal nanoparticles - a new perspective. CrystEngComm, 17(36), 6809-6830. https://doi.org/10.1039/C5CE01014D

Rivas, I., Mazaheri, M., Viana, M., Moreno, T., Clifford, S., He, C., ... Querol, X. (2017). Identification of technical problems affecting performance of DustTrak DRX aerosol monitors. Science of the Total Environment, 584-585, 849-855. https://doi.org/10.1016/j.scitotenv.2017.01.129

Russo, R. E., Mao, X., Gonzalez, J. J., Zorba, V., \& Yoo, J. (2013). Laser ablation in analytical chemistry. Analytical Chemistry, 85(13), 6162-6177. https://doi.org/10.1021/ac4005327

Salomão, R., Bôas, M. O. C. V., \& Pandolfelli, V. C. (2011). Porous alumina-spinel ceramics for high temperature applications. Ceramics International, 37(4), 1393-1399. https://doi.org/10.1016/j.ceramint.2011.01.012

Sánchez, E., García-Ten, J., Sanz, V., \& Moreno, A. (2010). Porcelain tile: Almost 30 years of steady scientific-technological evolution. Ceramics International, 36(3), 831-845. https://doi.org/10.1016/j.ceramint.2009.11.016

Sanchez, E., Orts, M. J., Garcia-Ten, J., \& Cantavella, V. (2001). Porcelain tile composition effect on phase formation and end products. American Ceramic Society Bulletin, 80(6), 43-49.

Saxena, N., Agarwal, A., \& Kanjilal, D. (2011). Effect of thermal annealing on the formation of silicon nanoclusters in SiOXfilms grown by PLD. Physica B: Condensed Matter, 406(11), 2148-2151. https://doi.org/10.1016/j.physb.2011.03.019

Sivayoganathan, M., Tan, B., \& Venkatakrishnan, K. (2012). Effect of mega-hertz repetition rate on the agglomerated particle size of femtosecond synthesized nanostructures. Optical Materials Express, 2(8), 987-995. https://doi.org/10.1364/OME.2.000987

Slaoui, A., Fogarassy, E., Fuchs, C., \& Siffert, P. (1992). Properties of silicon dioxide films prepared by pulsed-laser ablation. Journal of Applied Physics, 71(2), 590-596. https://doi.org/10.1063/1.350411

Sugioka, K., Meunier, M., \& Pique, A. (2010). Laser Precision Microfabrication. (K. Sugioka, M. Meunier, \& A. Piqué, Eds.) (Vol. 135). Berlin, Heidelberg: Springer Berlin Heidelberg. https://doi.org/10.1007/978-3-642-10523-4

van Broekhuizen, P. (2012). Nano Matters - Building Blocks for a Precautionary Approach. University of Amsterdam, Amsterdam. Retrieved from https://dare. uva.nl/search?identifier=84997b8a-0640-409e9017-c716ad8e1995

Viana, M., Fonseca, A. S., Querol, X., López-Lilao, A., Carpio, P., Salmatonidis, A., \& Monfort, E. (2017). Workplace exposure and release of ultrafine particles during atmospheric plasma spraying in the ceramic industry. Science of the Total Environment, 599-600, 2065-2073. https://doi.org/10.1016/j.scitotenv.2017.05.132

Viitanen, A. K., Uuksulainen, S., Koivisto, A. J., Hämeri, K., \& Kauppinen, T. (2017). Workplace measurements of ultrafine particles-A literature review. Annals of Work Exposures and Health, 61(7), 749-758. https://doi.org/10.1093/annweh/wxx049

Voliotis, A., Bezantakos, S., Giamarelou, M., Valenti, M., Kumar, P., \& Biskos, G. (2014). Nanoparticle emissions from traditional pottery manufacturing. Environ. Sci.: Processes Impacts, 16(6), 14891494. https://doi.org/10.1039/C3EM00709J

Weichenthal, S. (2012). Selected physiological effects of ultrafine particles in acute cardiovascular morbidity. Environmental Research, 115, 26-36. https://doi.org/10.1016/j.envres.2012.03.001

Zhang, R.-Q., Lifshitz, Y., \& Lee, S.-T. (2003). Oxide-Assisted Growth of Semiconducting Nanowires. 
Proper citation: https://doi.org/10.1016/i.jaerosci.2018.09.006

Advanced Materials, 15(78), 635-640. https://doi.org/10.1002/adma.200301641

Zhigilei, L. V., Lin, Z., \& Ivanov, D. S. (2009). Atomistic modeling of short pulse laser ablation of metals: Connections between melting, spallation, and phase explosion. Journal of Physical Chemistry C, 113(27), 11892-11906. https://doi.org/10.1021/jp902294m 


\section{Supplementary material}

Table S1. Chemical characterisation of the tiles under study.

\begin{tabular}{|c|c|c|c|c|c|c|c|}
\hline \multicolumn{2}{|c|}{ UBW } & \multicolumn{2}{|c|}{ UAW } & \multicolumn{2}{|c|}{ UPG } & \multicolumn{2}{|c|}{ Glaze $^{*}$} \\
\hline Component & $\begin{array}{c}\text { Content } \\
\left(w_{t} \%\right)\end{array}$ & Component & $\begin{array}{c}\text { Content } \\
\left(w_{t} \%\right)\end{array}$ & Component & $\begin{array}{c}\text { Content } \\
\left(w_{t} \%\right)\end{array}$ & Component & $\begin{array}{c}\text { Content } \\
\left(w_{t} \%\right)\end{array}$ \\
\hline $\mathrm{SiO}_{2}$ & 70.2 & $\mathrm{Al}_{2} \mathrm{O}_{3}$ & 97.3 & $\mathrm{SiO}_{2}$ & 70.6 & $\mathrm{SiO}_{2}$ & 55.7 \\
\hline $\mathrm{Al}_{2} \mathrm{O}_{3}$ & 19.8 & $\mathrm{SiO}_{2}$ & 1.3 & $\mathrm{Al}_{2} \mathrm{O}_{3}$ & 18.9 & $\mathrm{ZnO}$ & 12.0 \\
\hline $\mathrm{Na}_{2} \mathrm{O}$ & 5.8 & $\mathrm{MgO}$ & 0.5 & $\mathrm{Fe}_{2} \mathrm{O}_{3}$ & 1.0 & $\mathrm{CaO}$ & 10.2 \\
\hline $\mathrm{K}_{2} \mathrm{O}$ & 1.29 & $\mathrm{Na}_{2} \mathrm{O}$ & 0.2 & $\mathrm{Na}_{2} \mathrm{O}$ & 3.7 & $\mathrm{ZrO}_{2}$ & 7.0 \\
\hline $\mathrm{CaO}$ & 0.71 & $\mathrm{CaO}$ & 0.04 & $\mathrm{~K}_{2} \mathrm{O}$ & 1.9 & $\mathrm{Al}_{2} \mathrm{O}_{3}$ & 4.3 \\
\hline $\mathrm{TiO}_{2}$ & 0.62 & $\mathrm{Fe}_{2} \mathrm{O}_{3}$ & 0.03 & $\mathrm{CaO}$ & 0.6 & $\mathrm{~K}_{2} \mathrm{O}$ & 3.9 \\
\hline $\mathrm{Fe}_{2} \mathrm{O}_{3}$ & 0.51 & $\mathrm{~K}_{2} \mathrm{O}$ & 0.03 & $\mathrm{MgO}$ & 0.2 & $\mathrm{~B}_{2} \mathrm{O}_{3}$ & 3.6 \\
\hline $\mathrm{MgO}$ & 0.35 & $\mathrm{BaO}$ & 0.03 & $\mathrm{TiO}_{2}$ & 0.9 & $\mathrm{MgO}$ & 2.5 \\
\hline $\mathrm{P}_{2} \mathrm{O}_{5}$ & 0.13 & $\mathrm{TiO}_{2}$ & 0.01 & $\mathrm{MnO}$ & 0.01 & $\mathrm{HfO}_{2}$ & 0.14 \\
\hline $\mathrm{BaO}$ & 0.03 & $\mathrm{MnO}$ & 0.01 & $\mathrm{P}_{2} \mathrm{O}_{5}$ & 0.3 & $\mathrm{Na}_{2} \mathrm{O}$ & 0.10 \\
\hline $\mathrm{ZrO}_{2}$ & 0.03 & $\mathrm{P}_{2} \mathrm{O}_{5}$ & 0.01 & $\mathrm{Cr}_{2} \mathrm{O}_{3}$ & 0.3 & $\mathrm{Fe}_{2} \mathrm{O}_{3}$ & 0.05 \\
\hline $\mathrm{SrO}$ & 0.02 & & & $\mathrm{ZrO}_{2}$ & 1.0 & $\mathrm{TiO}_{2}$ & 0.05 \\
\hline $\mathrm{MnO}$ & 0.01 & & & & & $\begin{array}{l}\mathrm{PbO} \\
\mathrm{P}_{2} \mathrm{O}_{5} \\
\mathrm{BaO} \\
\mathrm{Li}_{2} \mathrm{O} \\
\mathrm{SrO}\end{array}$ & $\begin{array}{c}0.03 \\
0.03 \\
0.01 \\
<0.01 \\
<0.01\end{array}$ \\
\hline
\end{tabular}

${ }^{*}$ The chemical composition refers only to the glaze, and not the body of the GER tile, since that was the part processed by the laser 

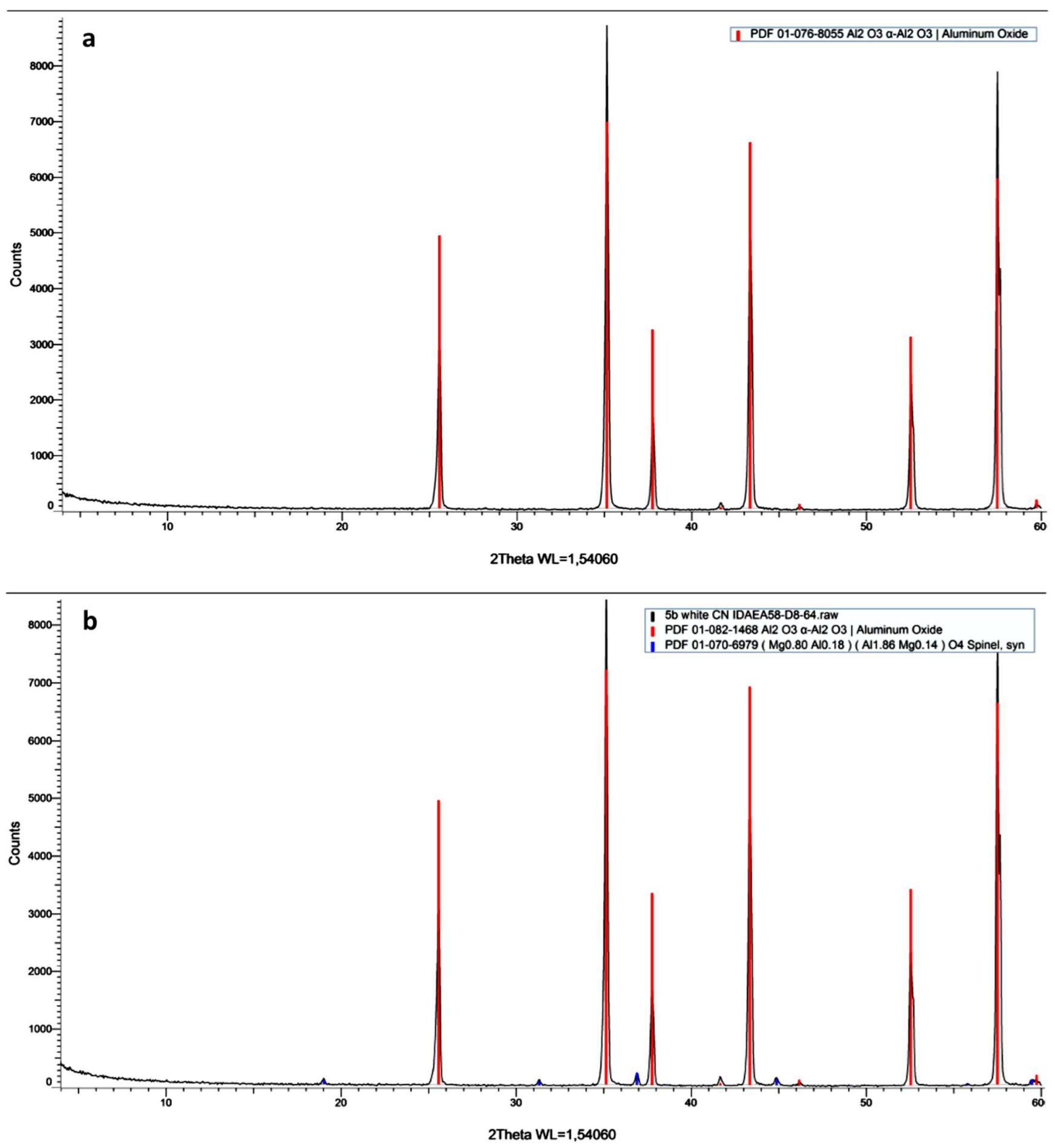

Figure S1. X-ray powder diffraction pattern of UAW $\alpha$-Alumina tiles, (a) pure $\alpha$-Alumina and (b) the tile with dominant phase of $\alpha$-Alumina and a minor phase (trace) of spinel MgAlO 


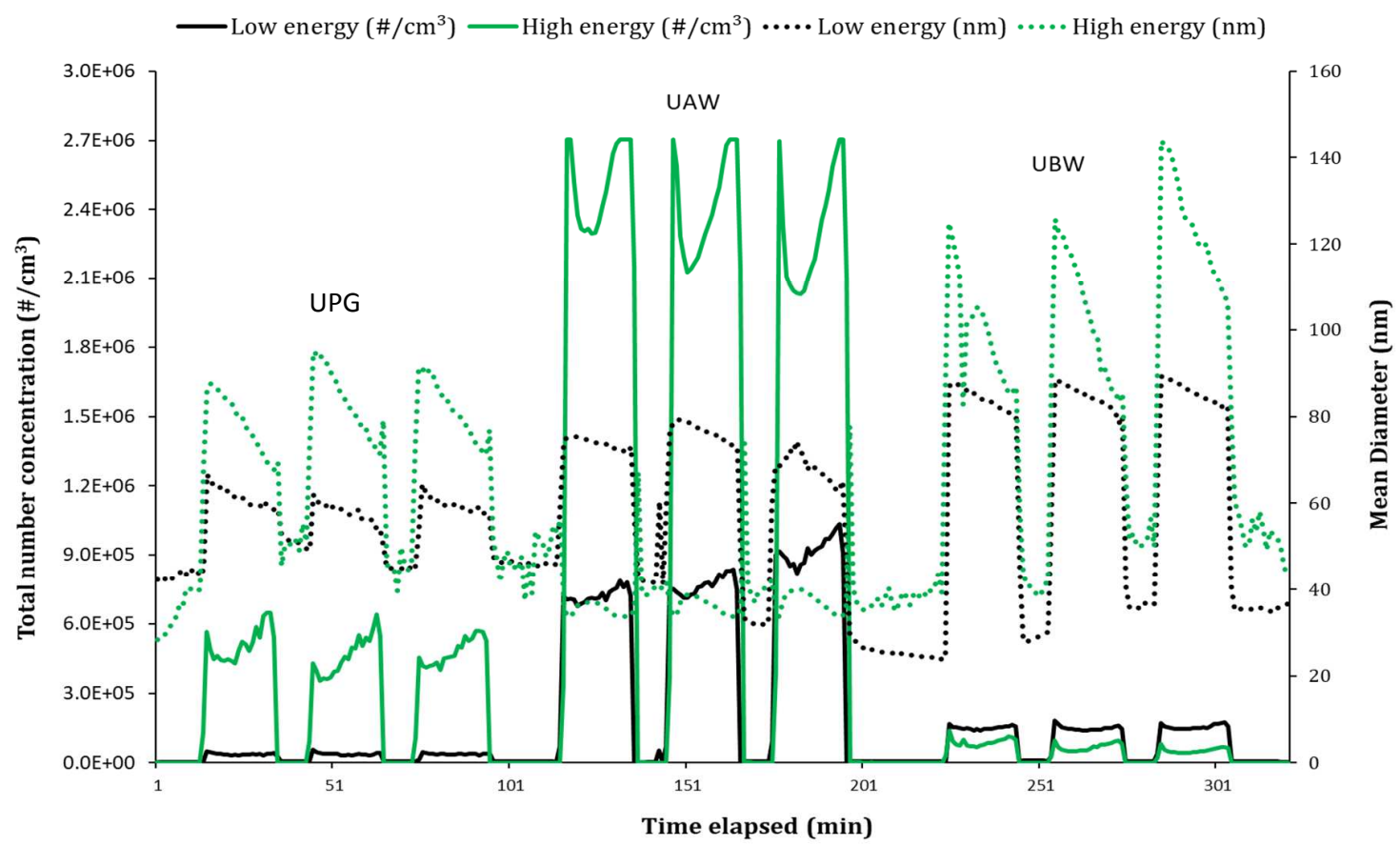

Figure S2. Mean particle diameter $(\mathrm{nm})$ and number concentration $(10-700 \mathrm{~nm})$ for low and high energy settings, monitored with DiSCmini.

Table S2. Laser parameters and energy settings applied for the two laser set-ups.

\begin{tabular}{ccccc}
\hline \multirow{2}{*}{ Energy settings } & \multicolumn{2}{c}{ Near-IR laser } & \multicolumn{2}{c}{ Mid-IR laser } \\
& Low & High & Standard & Low \\
\hline Laser power (W) & 11.5 & 20 & 30 & 15 \\
Duty cycle (\%) & & & 0.8 & 0.8 \\
Spacing between lines (mm) & 0.02 & 0.03 & 4 & 4 \\
Laser velocity (m/min) & 1.5 & 1.5 & 20 & 15 \\
Frequency (kHz) & 20 & 25 & 50000 & 66667 \\
Pulse duration (ns) & 100 & 200 & &
\end{tabular}



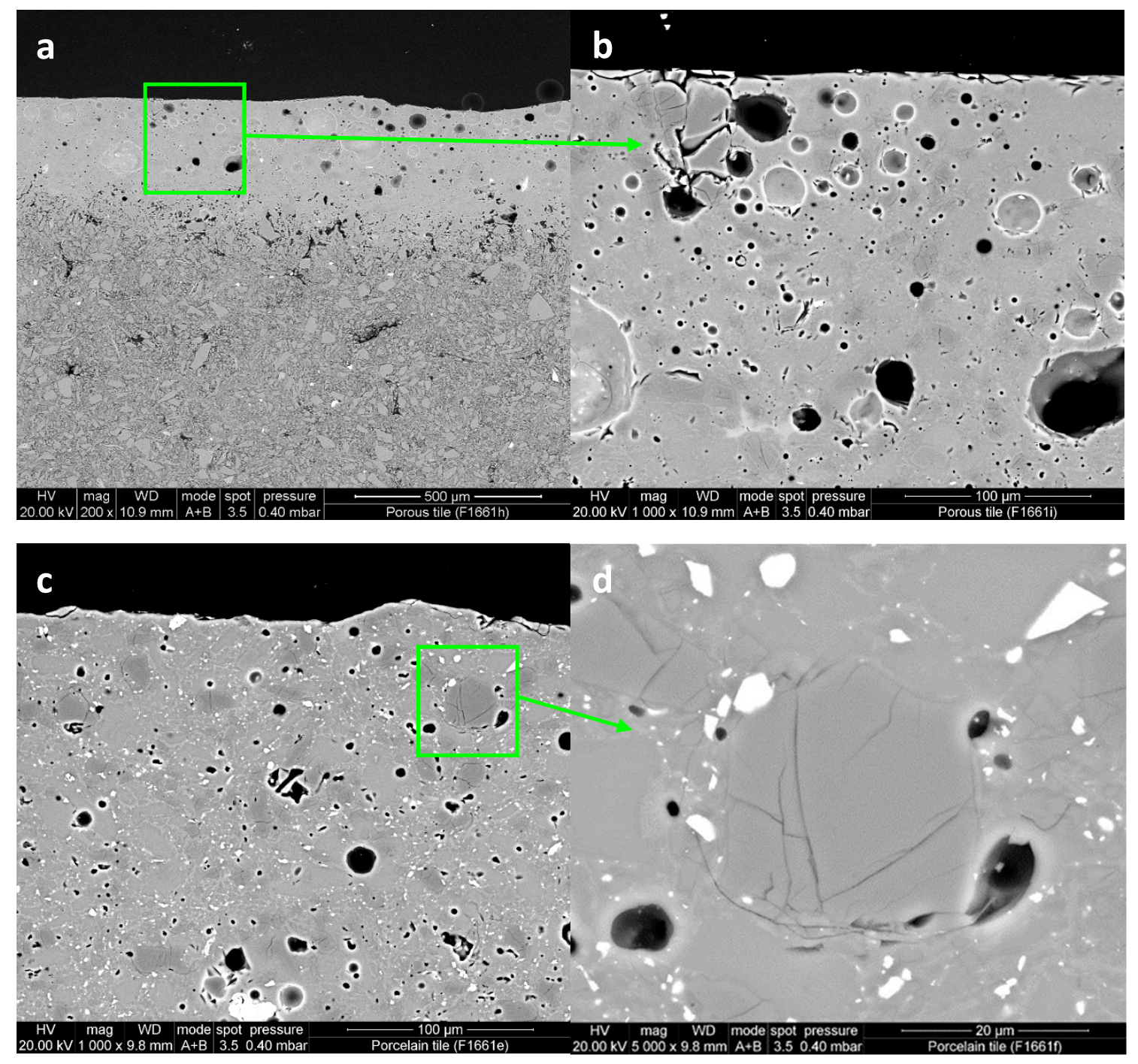

Figure S3. SEM images of the surfaces of untreated porcelain tiles. UBW $(a, b)$ and UPG (c,d) 


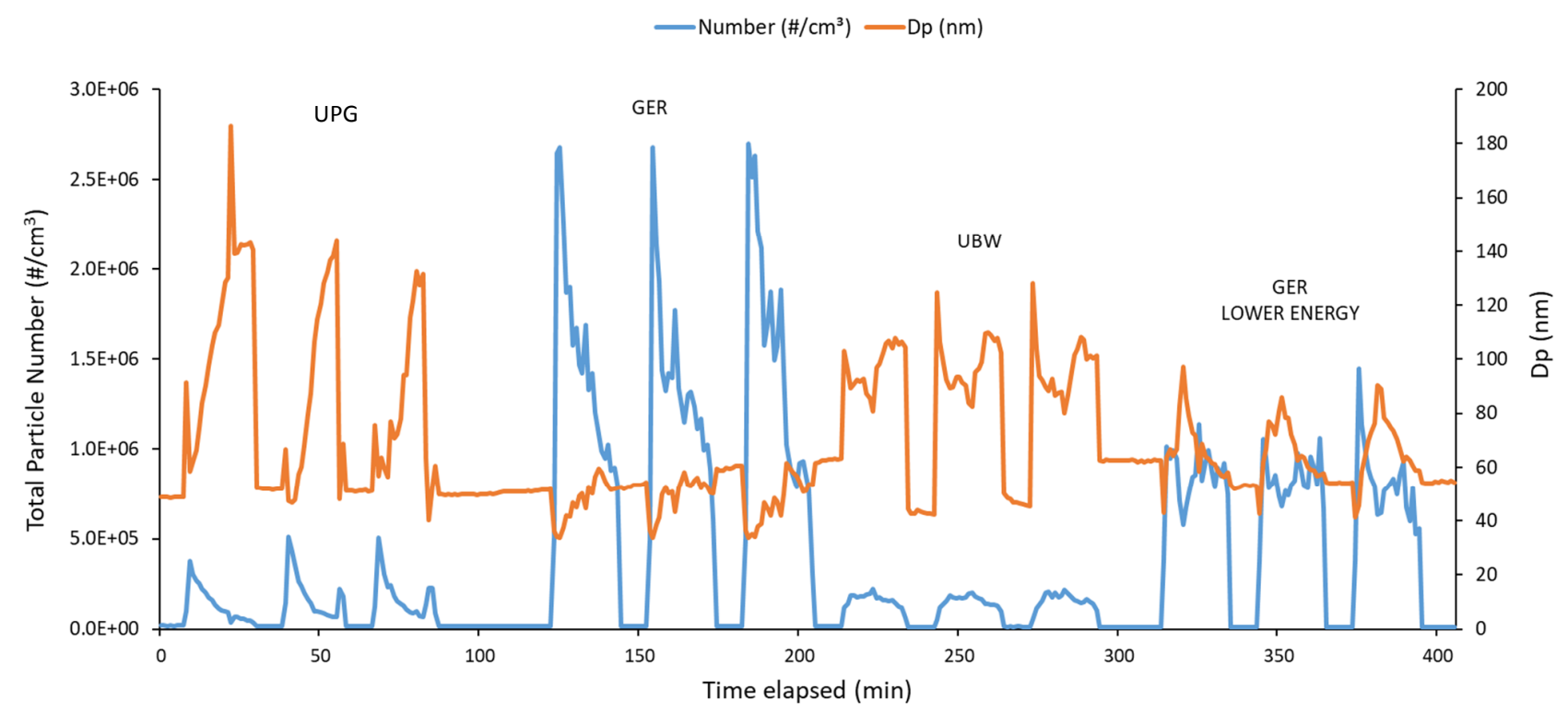

Figure S4. Mean particle diameter $(\mathrm{nm})$ and total particle number concentration $(10-700 \mathrm{~nm})$ for the different tiles and energy settings during ablation with the mid-IR laser.

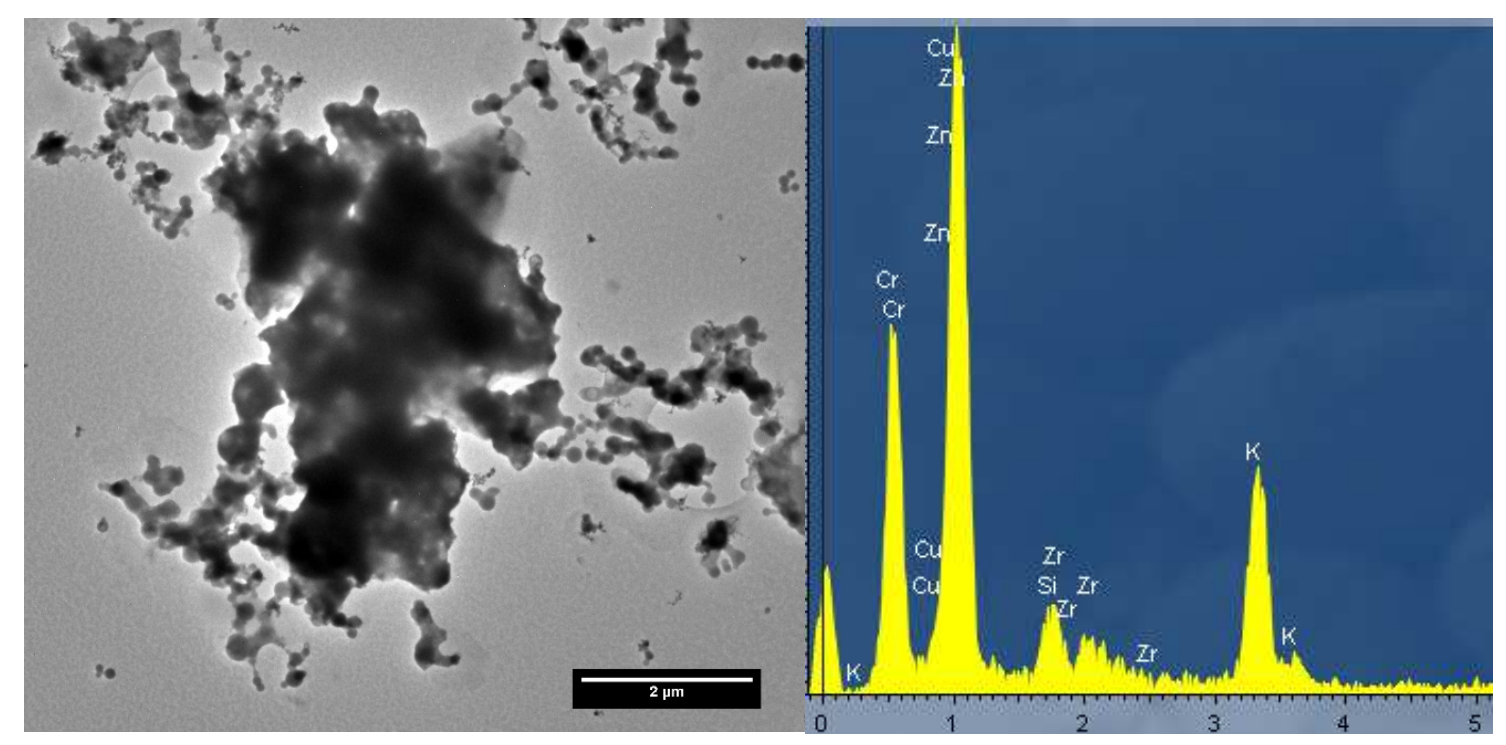

Figure S5. TEM image and EDX spectra of NPs emitted during GER ablation with the mid-IR laser. 
Proper citation: https://doi.org/10.1016/i.jaerosci.2018.09.006

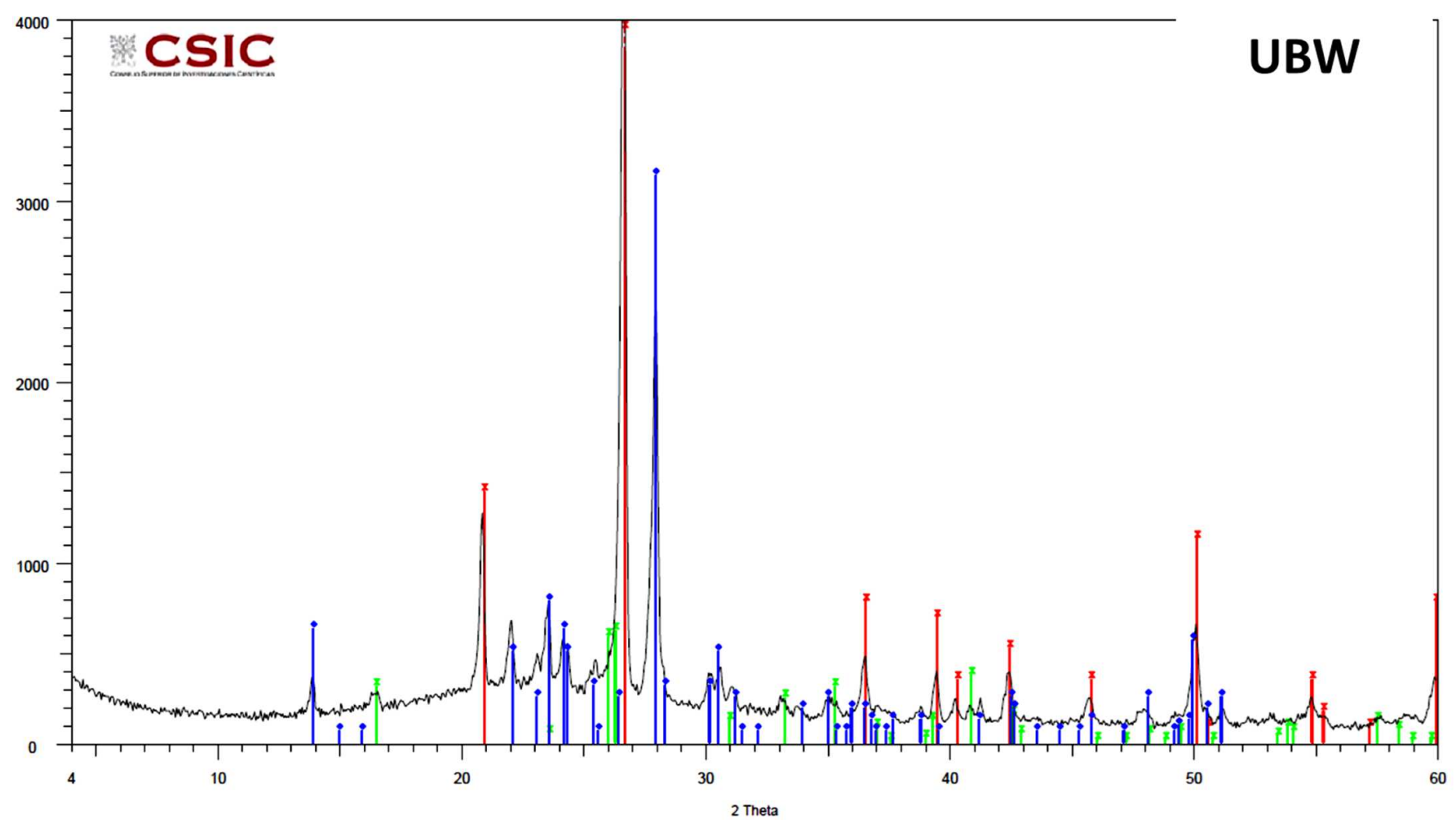

WUPWE - File: IDAEA58-D8-62.raw - Type: $2 \mathrm{Th}$ Th locked - Step: $0.050^{\circ}$ - Step time: $3 . \mathrm{s}$ - Theta: $2.000^{\circ}$ - Generator kV: $40 \mathrm{kV}$ - Generator mA: $40 \mathrm{~mA}$ - Operator. Natalia Moreno Z $00-046-1045\left(\right.$ (") $^{-}$Quartz, syn - SiO2

- 00-009-0466 (") - Albite, ordered - NaAISi3Os

Z 00-015-0776 (I) - Mullite, syn - Al6Si2O13

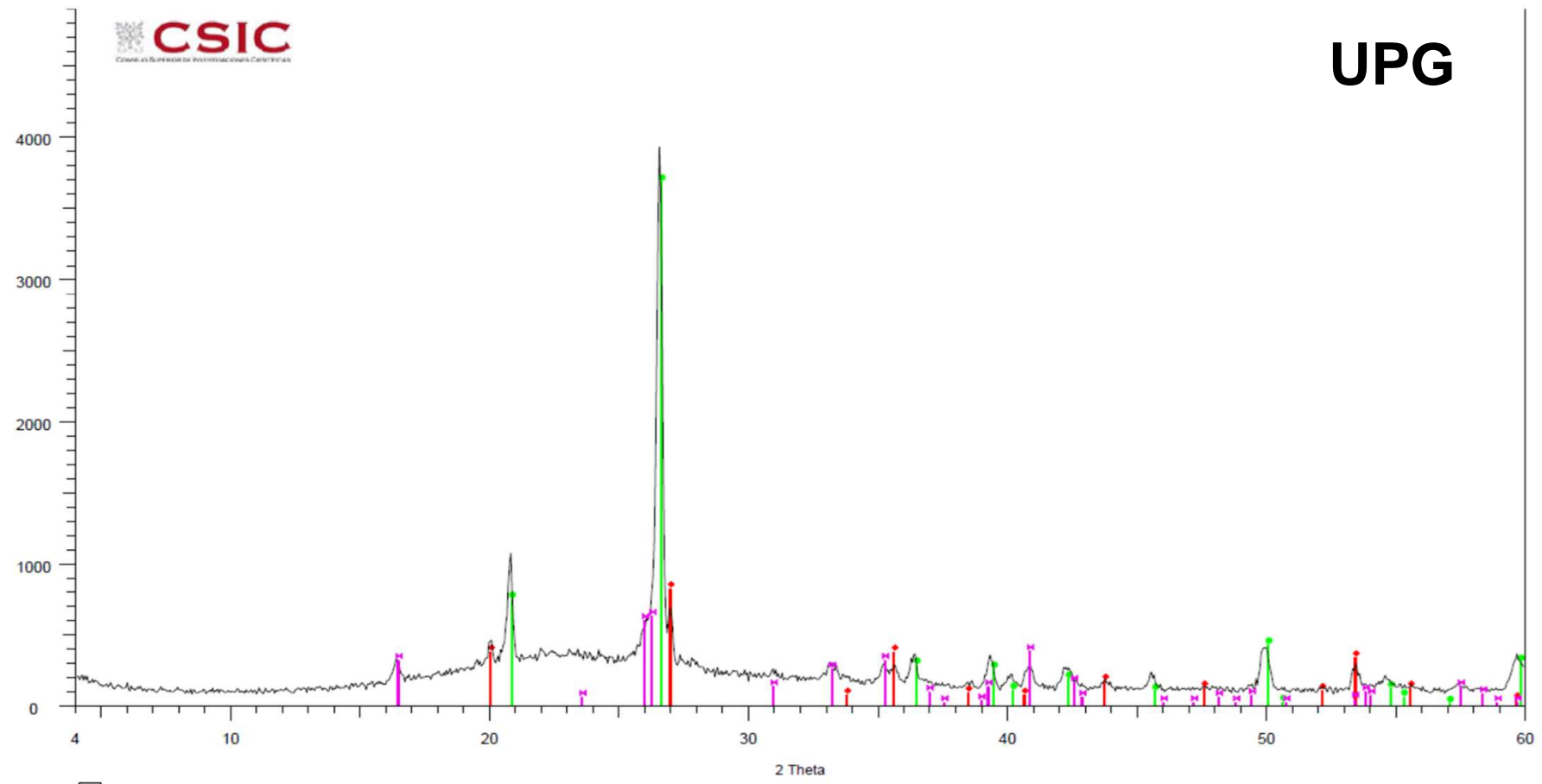

WUUGP - File: IDAEA58-D8-60.raw - Type: $2 \mathrm{Th} / \mathrm{Th}$ locked - Step: $0.050^{\circ}$ - Step time: $3 . \mathrm{s}$ - Theta: $2.000^{\circ}$ - Generator $\mathrm{kV}: 40 \mathrm{kV}$ - Generator mA: $40 \mathrm{~mA}$ - Operator. Natalia Moreno - 00-006-0266 (") - Zircon - ZrSiO4

01-085-0457 (C) - Silicon Oxide - $\mathrm{SiO} 2$

M 00-015-0776 (I) - Mullite, syn - Al6Si2O13 


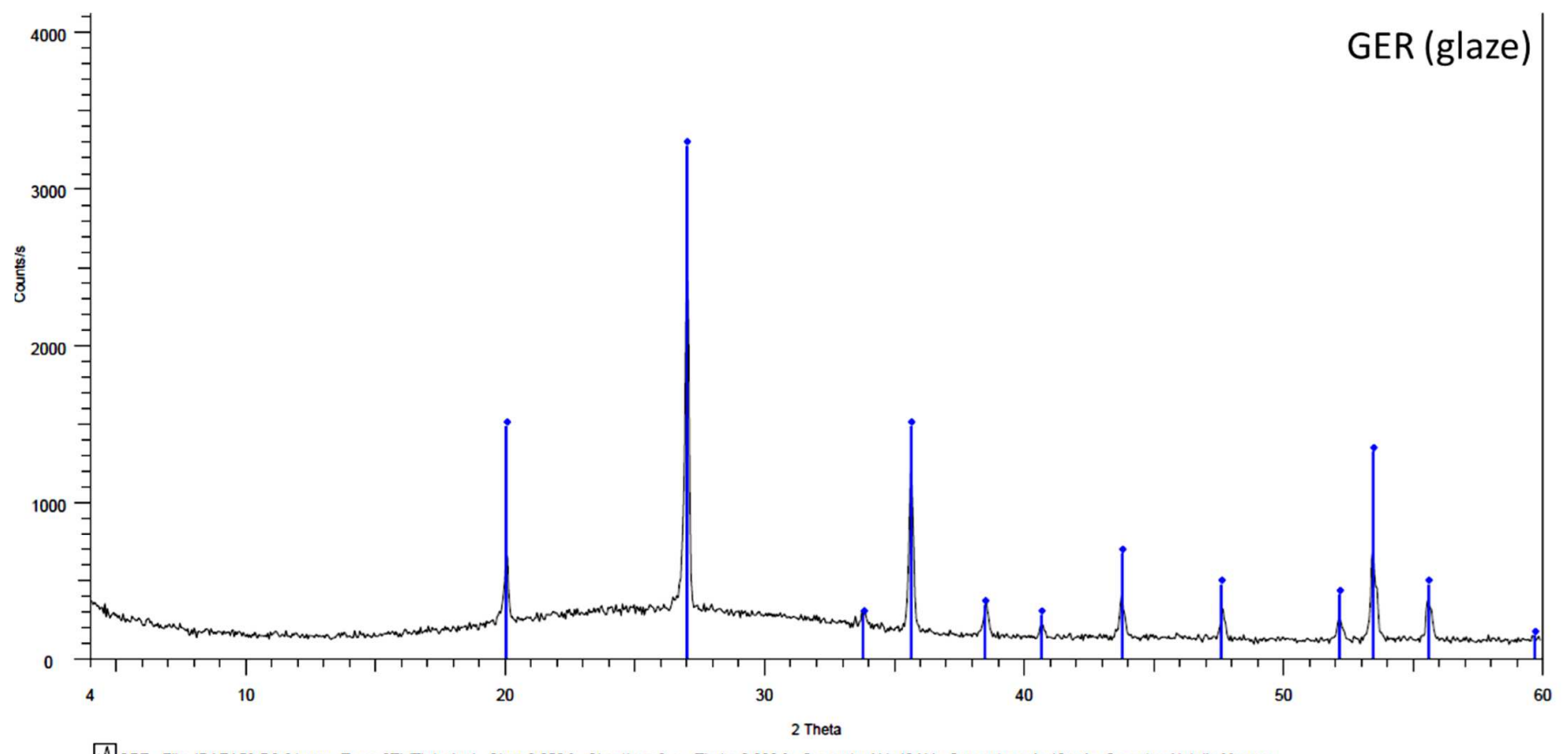

WTE - File: IDAEA58-D8-61.raw - Type: $2 \mathrm{Th} / \mathrm{Th}$ locked - Step: $0.050^{\circ}$ - Step time: $3 . \mathrm{s}$ - Theta: $2.000^{\circ}$ - Generator $\mathrm{kV}: 40 \mathrm{kV}$ - Generator mA: $40 \mathrm{~mA}$ - Operator. Natalia Moreno 00-006-0266 (*) - Zircon - ZrSiO4

Figure S6. Mineralogical - crystal phase - analysis from the surface of the ceramic tiles (UBW, UPG, GER)
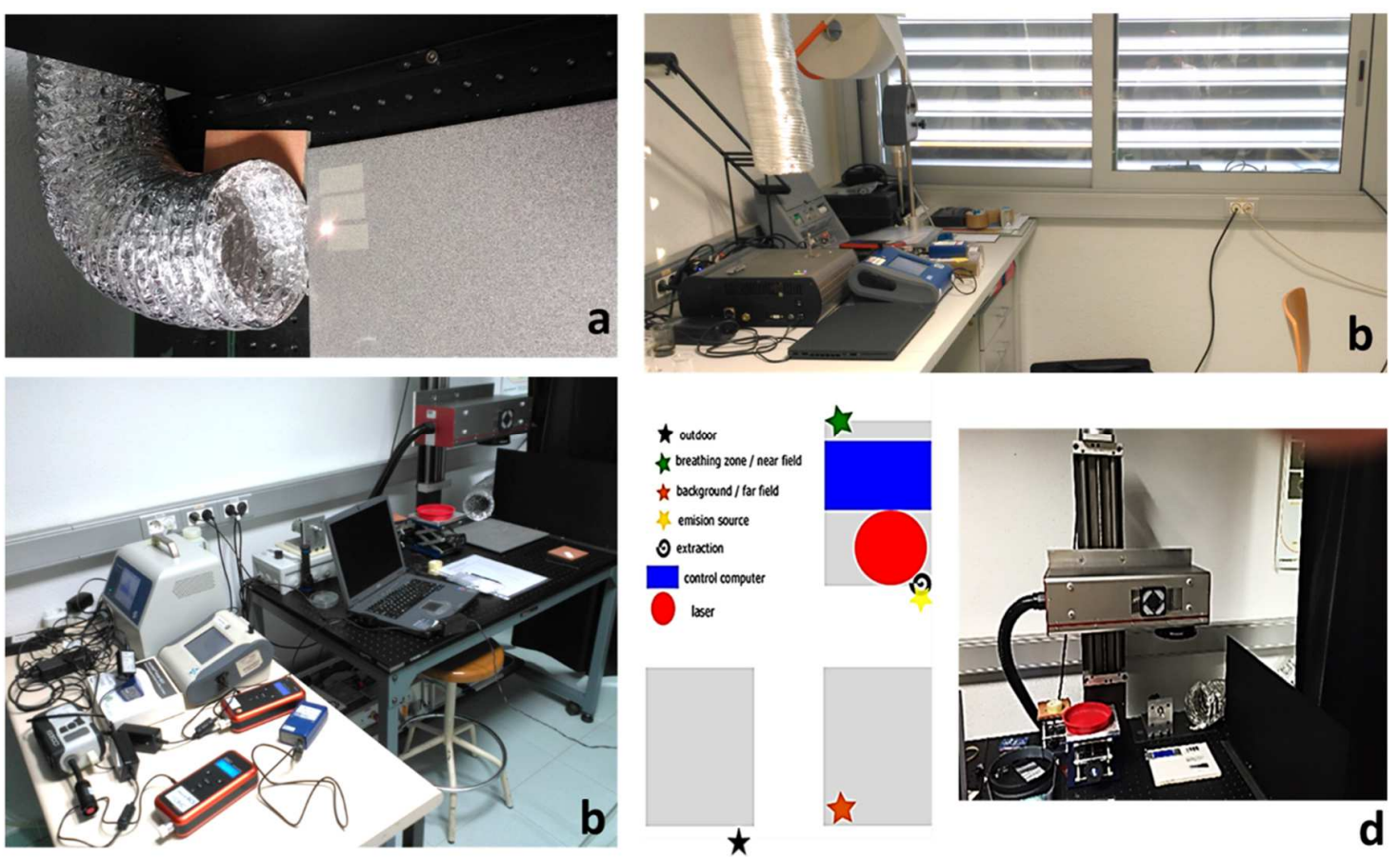

Figure S7. a) Incident laser beam during the PLA of UPG ( $3^{\text {rd }}$ repetition), b) instruments in the far-field location, $\mathrm{c}$ ) instruments in the near-field location (the laser was operated from the computer), d) layout of the monitoring location (left) and the emission source location (right) 